University of Zurich

Department of Economics

Working Paper Series

ISSN 1664-7041 (print)

ISSN 1664-705X (online)

Working Paper No. 346

\title{
Prosociality predicts health behaviors during the COVID-19 pandemic
}

Pol Campos-Mercade, Armando N. Meier, Florian H. Schneider and Erik Wengström

May 2020 


\title{
Prosociality predicts health behaviors
}

\section{during the COVID-19 pandemic}

\author{
Pol Campos-Mercade ${ }^{\star}$ Armando N. Meier ${ }^{\dagger}$ \\ Florian H. Schneider ${ }^{\ddagger}$ Erik Wengström ${ }^{\times}$
}

Latest version: Link

First version: May 8, 2020 - This version: May 17, 2020

\begin{abstract}
Socially responsible behavior is crucial for slowing the spread of infectious diseases. However, economic and epidemiological models of disease transmission abstract from prosocial motivations as a driver of behaviors that impact the health of others. In an incentivized study, we show that a large majority of people are very reluctant to put others at risk for their personal benefit. Moreover, this experimental measure of prosociality predicts health behaviors during the COVID-19 pandemic, measured in a separate and ostensibly unrelated study with the same people. Prosocial individuals are more likely to follow physical distancing guidelines, stay home when sick, and buy face masks. We also find that prosociality measured two years before the pandemic predicts health behaviors during the pandemic. Our findings indicate that prosociality is a stable, long-term predictor of policy-relevant behaviors, suggesting that the impact of policies on a population may depend on the degree of prosociality.
\end{abstract}

JEL Classifications: D01, D91, I12, I18

Keywords: social preferences, health behavior, externalities, COVID-19

${ }^{\star}$ Pol Campos-Mercade, University of Copenhagen (pcm@econ.ku.dk)

${ }^{\dagger}$ Armando N. Meier, University of Chicago Booth School of Business (armando.meier@chicagobooth.edu)

${ }^{\ddagger}$ Florian H. Schneider, University of Zurich (florian.schneider2@uzh.ch)

${ }^{\times}$Erik Wengström, Lund University and Hanken School of Economics (erik.wengstrom@nek.lu.se)

We thank seminar participants at the University of Chicago, University of Zurich, Helsinki GSE and the University of Basel as well as Håkan Holm, Michel Maréchal, Marco Piovesan, Julien Senn, Mirco Tonin, Vanessa Valero, Roel van Veldhuizen, and Roberto Weber for helpful comments. Armando Meier acknowledges funding from Swiss National Science Foundation grant P2BSP1_181847, and Erik Wengström funding from the Torsten Söderberg foundation. Ethical approval was obtained from the Human Subjects Committee of the Faculty of Economics, Business Administration, and Information Technology at University of Zurich. The preregistration plan can be found on https://osf.io/vp5c6/ . 


\section{Introduction}

Socially responsible behavior is crucial for slowing the spread of infectious diseases. However, economic and epidemiological models of disease transmission abstract from prosocial motivations as a driver of behaviors that impact others' health. ${ }^{1}$ If people neglect the social impact of their behavior, for example by violating physical distancing guidelines, they risk other people's health and put a strain on the public health system. Many countries have thus vigorously closed down public life at the peak of the COVID-19 pandemic. Other countries, most notably Sweden, have relied on recommendations rather than restrictions, thereby counting on citizens to voluntarily internalize the externalities of their behavior. As countries lift their restrictions, understanding whether and to what extent people are influenced by the social impact of their health behaviors is key for policy-making (Farboodi, Jarosch and Shimer, 2020).

A large literature shows that many people consider the social impacts of their behavior; that is, people have other-regarding or "social" preferences (Loewenstein, Thompson and Bazerman, 1989; Fehr and Schmidt, 1999; Bolton and Ockenfels, 2000; Andreoni and Miller, 2002; Charness and Rabin, 2002; Henrich et al., 2005; Dawes et al., 2007; Almås et al., 2010; Crockett et al., 2010; Tricomi et al., 2010; Fisman et al., 2015; Bartling, Weber and Yao, 2015). While social preferences enter many realms of decision making, ${ }^{2}$ less is known about whether social preferences explain behaviors in the domain of health. There are important reasons to believe that social preferences may not explain health behaviors, particularly during pandemics. Selfish motives, such as worries about getting infected, could trump prosocial motivations. Moreover, research in psychology and economics suggests that people may use uncertainty about the social impact of their health behaviors as an excuse to act selfishly (Haisley and Weber, 2010; Exley, 2016; Bavel et al., 2020). Therefore, the degree to which individuals' concerns for social impacts drive behavior during a pandemic remains an open and important question.

\footnotetext{
${ }^{1}$ While epidemiological models of disease transmission typically do not model individual behavior explicitly (Kermack and McKendrick, 1927; Peak et al., 2017; Prem et al., 2020; Fang, Nie and Penny, 2020), economic models generally assume that people are exclusively self-interested (Eichenbaum, Rebelo and Trabandt, 2020; Krueger, Uhlig and Xie, 2020; Bethune and Korinek, 2020). Garibaldi, Moen and Pissarides (2020), for example, state that people "ignore the costs they cause when they transmit the disease to others [...] these externalities justify government action that imposes more social distancing than people will choose."

${ }^{2}$ Examples include redistribution (Fisman, Jakiela and Kariv, 2017; Almås, Cappelen and Tungodden, 2020; Epper, Fehr and Senn, 2020) and public goods production (Fehr and Gächter, 2002; Rand et al., 2009; Hauser et al., 2014; Lergetporer et al., 2014; Gächter, Kölle and Quercia, 2017; Molleman et al., 2019).
} 
In this paper, we study the link between social preferences and health behaviors during the COVID-19 pandemic. We collect measures of social preferences and health behaviors in two separate surveys involving a broadly representative sample of the Swedish population $(N=967)$. We preregistered the data collection and analysis. In the health behavior survey, we collect information on a first set of thirteen health behaviors during the COVID19 pandemic, including whether participants maintain physical distancing, follow hygiene recommendations, and stay home when sick. The second set of behaviors involve three actual choices during the study where participants decide whether to buy a cloth face mask, donate to fighting COVID-19, and click on links to learn more about how to help and protect others during the pandemic. In the social preferences survey, we measure prosociality using an incentivized game in which participants can expose others to risk for their own benefit. ${ }^{3}$ We use this game because many health behaviors during a pandemic, such as leaving home when sick, include similar tradeoffs between personal benefit and exposing others to risk. The game does not involve any framing that is linked to COVID-19, but instead measures a general willingness to forgo personal benefit to mitigate risks to others. We match these data with an additional prosociality measure collected for a subset of the same participants two years before the pandemic.

We find that people are generally very averse to expose others to risk for their own benefit. A large share of participants do not want to put others at risk, even if the potential gains are large. More importantly, we also find that social preferences predict health behaviors that impact others. More prosocial people are more likely to follow physical distancing and hygiene recommendations, buy a cloth face mask, donate to fighting COVID-19, and inform themselves about how they can protect others. Moving a person from least prosocial to most prosocial increases most health behaviors by around 0.2 to 0.4 of a standard deviation. The effects are robust to sociodemographic controls and cannot be explained by risk preferences, time preferences, beliefs, or personality traits (Big Five). We also show that prosociality measured two years before the pandemic predicts health behaviors in response to COVID19. Taken together, the results reveal that social preferences have substantial and stable explanatory power for responsible health behaviors.

\footnotetext{
${ }^{3}$ We thereby build on previous work on social preferences in risky environments, see, e.g., Haisley and Weber (2010); Krawczyk and Le Lec (2010); Brock, Lange and Ozbay (2013); Freundt and Lange (2017); Andersson et al. (2020).
} 
We focus on Sweden because, despite having a similar number of COVID-19 cases per capita as countries such as the US and the UK, policymakers have avoided mandating strict stay-at-home policies. Restaurants, malls, and gyms remained open at the time of data collection. This represents a situation in which responsible health behavior is very important to avoid the spread of the virus. This situation is also similar to the one that most countries will face as they phase out stronger regulations. Furthermore, while some media coverage may lead to the impression that Swedes are particularly prosocial, global data on prosociality indicates that Swedes are not more prosocial than the population of many other Western countries, such as Canada, Germany, Spain, the UK, and the US (Falk et al., 2018; WGI, 2018). Taken together, Sweden offers an ideal laboratory to study prosociality and behavior in reaction to the COVID-19 pandemic.

We collect our data using two ostensibly unrelated and incentivized studies. A potential concern of analyzing social preferences and health behavior using survey methods is that experimenter demand effects may lead respondents to answer consistently across questions (Rosenthal, 1966; Zizzo, 2010; De Quidt, Haushofer and Roth, 2018). Our design addresses this concern in two ways. First, social preferences and health behavior are measured in two different surveys. We blur the connection between the two surveys by letting at least one week pass between the two surveys and by using different fonts, formats, and university affiliations. Participants therefore likely perceive the two surveys as independent research projects. Second, we incentivize the social preference measure and several of the health behavior measures by implementing the choices of a random subset of respondents, meaning that some of their choices have real consequences.

Another key advantage of our design is that we can match our newly collected data with participants' responses to an experimentally validated survey measure of prosociality (Falk et al., 2018) collected two years before the COVID-19 pandemic as part of an independent study. While we have these data only for a subset of participants and therefore have less statistical power, we can examine whether there is a positive relationship between current health behavior and prosociality measured two years before the pandemic. In addition to allowing us to examine prosociality as a long-term predictor of health behavior, this also helps alleviate potential concerns that prosociality may have changed during the COVID-19 outbreak (Branas-Garza et al., 2020). 
Our findings contribute to an extensive literature that studies the determinants of health behaviors. This literature shows that individual-level risk aversion, patience, and personality traits are all closely linked to health behaviors. ${ }^{4}$ We add to the literature by showing that, beyond these factors, prosociality is an important and independent determinant of behaviors that are valuable for supporting public health. The relation between prosociality and healthrelated behaviors that we document cannot be explained by motives such as risk preferences, time preferences and worries about being infected. Moreover, we document that prosociality predicts behaviors above and beyond individual differences in personality and trust.

We also complement a growing literature that examines whether information that highlights the social consequences of certain health-related behaviors can induce greater adherence to policy recommendations (Hershey et al., 1994; Grant and Hofmann, 2011; Ibuka et al., 2014; Li et al., 2016; Betsch et al., 2017; Brewer et al., 2017; Jordan, Yoeli and Rand, 2020; Everett et al., 2020). In contrast to our paper, this literature studies how to best change health behavior, without focusing on individual differences in the underlying motivations. However, the effectiveness of such informational interventions will often rest on the degree to which people care about the social impacts of their actions. Our results thus suggest that informing people about the social impact of their behavior can be effective precisely because many people care about such impacts, and are willing to incur costs to promote positive social outcomes.

This paper is organized as follows. Section 2 describes the design of the surveys and defines the main variables of the study. Section 3 presents the main results. Section 4 concludes and discusses policy implications of our results.

\footnotetext{
${ }^{4}$ Previous literature has shown that risk preferences (see, e.g., Anderson and Mellor 2008; Dohmen et al. 2011; Galizzi, Machado and Miniaci 2016), time preferences and self-control (Chapman and Coups, 1999; Chesson et al., 2006; DellaVigna and Malmendier, 2006; Chabris et al., 2008; Harrison, Lau and Rutström, 2010; Moffitt et al., 2011; Chen, 2013; Sutter et al., 2013; Stutzer and Meier, 2016; Bai et al., 2017; Haushofer, John and Orkin, 2019; Schilbach, 2019) as well as personality (Booth-Kewley and Vickers, 1994; Ingledew and Brunning, 1999; Vollrath and Torgersen, 2002; Bogg and Roberts, 2004; Kern and Friedman, 2008; Rustichini et al., 2012; Bogg and Roberts, 2013; Friedman and Kern, 2014; Strickhouser, Zell and Krizan, 2017; Turiano et al., 2018), matter for health behaviors. See Galizzi and Wiesen (2018) for a recent review of the literature linking experimentally and incentive compatible measures of preferences to health behaviors and Cawley and Ruhm (2011) for a review of the theoretical economic literature modelling risky health behaviors. In the context of the COVID-19 pandemic, several contemporaneous papers examine the relation between health behaviors and self-reported risk and time preferences, trust, and personality (Zettler et al., 2020; Müller and Rau, 2020; Briscese et al., 2020; Thunström et al., 2020).
} 


\section{Design}

Data collection and sample. We invite a representative sample of the Swedish population (in terms of age, gender, and Nuts2 regions) to answer two surveys: the first survey collected measures of health behaviors during the COVID-19 pandemic, and the second survey collected measures of social preferences (Appendix Section C gives sample statistics).

The two online surveys were sent by the survey company Enkätfabriken in April 2020. One week after participants finished the health behavior survey, we invited them to participate in the social preferences survey. We only invited participants to the second survey if they finished the health behavior survey in more than 5 minutes. We expect this to be the minimum amount of time needed to fill out the survey considerately. As preregistered, we drop from the analysis all participants who completed the survey in less than 5 minutes.

We also use data from an earlier, independent, survey fielded in 2018 which contains an alternative measure of prosociality (Hardardottir, Gerdtham and Wengström, 2019). When sending the surveys in April 2020, the survey company also targeted participants who filled out the 2018 survey.

In total, 1,630 people responded the health behavior survey $(1,505$ people in more than 5 minutes) and 1,067 people responded to the social preferences survey. We can therefore match the two surveys for 1,067 participants. Of those, 967 answered all questions in both surveys and finished the health behavior survey in more than five minutes. Importantly, we show that sample retention is orthogonal to social preferences (Appendix Table C.1). We can also link the health behavior data to the measures of prosociality collected in 2018 for 197 participants.

Social preferences survey. In the social preferences survey, we measure participants' willingness to expose others to risk with a game that builds on the dictator game, the Risk Dictator Game. We do not mention COVID-19 in any way when (and before) we measure these social preferences.

In the Risk Dictator Game, a dictator and a recipient get $\$ 10$ each (= SEK 100). The dictator then decides with what risk $(0 \%, 20 \%, 40 \%, 60 \%, 80 \%$, or $100 \%)$ the recipient loses his/her $\$ 10$. The dictator receives $\$ \mathrm{X}$ for each additional $20 \%$ risk put on the recipient (Table 1 describes all the options). All participants in the social preferences survey make a choice for $\$ \mathrm{X}$ taking the values $\$ 0.5, \$ 1, \$ 2, \$ 5$ and $\$ 10$, resulting in five choices per 
participant. To make sure that participants understand the game, they have to correctly answer three comprehension questions before they can make their choices.

As preregistered, we construct our measure of participants' prosociality as follows. Let $r\left(c_{i, g}\right) \in\{0,0.2,0.4,0.6,0.8,1\}$ be the risk that participant $i$ puts on the recipient in game $g \in\{1, \ldots, 5\}$. We measure $i$ 's prosociality as $1-1 / 5 \sum_{g=1}^{5} r\left(c_{i, g}\right)$, that is, one minus the average risk that participant $i$ puts on the recipient. The measure has a value of 1 if the participant always chooses the option that puts no risk on the recipient, and 0 if the participant always chooses the option that puts the maximal risk on the recipient.

Table 1: Risk Dictator Game payoff table

\begin{tabular}{ccccccc}
\hline \hline Dictator's choice & 1 & 2 & 3 & 4 & 5 & 6 \\
\hline Dictator's payoff in $\$$ & 10 & $10+\mathrm{X}$ & $10+2 \mathrm{X}$ & $10+3 \mathrm{X}$ & $10+4 \mathrm{X}$ & $10+5 \mathrm{X}$ \\
\hline Risk that the recipient loses $\$ 10$ & $0 \%$ & $20 \%$ & $40 \%$ & $60 \%$ & $80 \%$ & $100 \%$ \\
\hline \hline
\end{tabular}

Note: Participants make a choice in the role of dictator for $\mathrm{X}$ taking the values $\$ 0.5, \$ 1, \$ 2, \$ 5$ and $\$ 10$, resulting in five choices per participant.

In addition to these five choices, participants make one more incentivized choice where they get $\$ 10$ and decide how much to invest in a risky asset. If the investment fails, which happens with $50 \%$ chance, they lose all the invested money. If the investment succeeds, which happens with $50 \%$ chance, the money they invested is multiplied by 2.5 . This is a common task to measure risk preferences (Gneezy and Potters 1997, see Appendix Section D for the instructions). Participants have to correctly answer two comprehension questions before they make their choices.

We incentivize these questions by implementing the choice that $1 / 10$ of the participants make in one of the six questions. If the question that is selected corresponds to the Risk Dictator Game, we randomly match the participant with another participant who plays the role of the recipient. Instructions for the task are given in Appendix Section D.

We also collect data on further, experimentally validated, ${ }^{5}$ measures of prosociality (Falk et al., 2018):

- Prosociality GPS: How willing are you to give to good causes without expecting anything in return? (Values from 0 meaning "completely unwilling to do so," to 10 meaning "very willing to do so." are allowed.)

\footnotetext{
${ }^{5}$ Several papers have shown that this measure predicts actual behavior in laboratory experiments (Falk et al., 2018; Vieider et al., 2015; Galizzi, Machado and Miniaci, 2016; Dohmen et al., 2011).
} 
- Prosociality GPS, item 2: Imagine the following situation: You receive unexpectedly SEK 18,000 today. How much of that sum would you donate to a charitable cause? (Values between 0 and 18,000 are allowed.)

We collect these two measures for two reasons. First, we have the same measure of Prosociality GPS (first question) in the data of the 2018 study. Having the same measure in 2020 allows us to compare the correlation between health behaviors and prosociality in 2018 with the corresponding correlation in 2020. In addition, the two measures allow us to investigate the robustness of our findings by using alternative measures of prosociality.

In addition, we also collect information on participants' beliefs about the risk preferences of the other participants, job, motivations for the job participants do, importance of friends, additional personal characteristics using a short version of the Big Five (Gosling, Rentfrow and Swann, 2003), perceived life expectancy, worries regarding COVID-19, and self-reported risk and time preferences based on the Global Preference Survey (Falk et al., 2018).

Health behavior survey. In the health behavior survey, we collect information on how strongly (on a scale from 1 to 7 ) people follow thirteen different behaviors that are important to reduce the spread of the COVID-19. Note that these were the first questions participants saw and that we did not hint in any way at social preferences nor the social impact of these behaviors. We aggregate those behaviors into four indices, as described in the preregistration. To build the indices, we measured the perceptions of an independent sample of 100 Swedes regarding whether each health behavior protects others and oneself and grouped them based on similar perceptions (see the description in Appendix Table A.1). We then built the following four indices:

- Health behaviors index 1 (behaviors that impact others strongly, me moderately): coughing and sneezing into elbow, self-isolating if one shows symptoms, informing others one had contact with if one shows symptoms, and covering the face if one shows symptoms (e.g., by wearing a mask).

- Health behaviors index 2 (behaviors that impact others strongly, me strongly): avoiding social contacts, informing oneself how spread can be prevented, keeping at least two meters distance, and refraining from private domestic trips. 
- Health behaviors index 3 (behaviors that impact others strongly and me strongly): how often people left their home during the last seven days to buy things other than food and drugs, to do physical activities with other people, and to hang out in person with friends and relatives who do not live in the same household. ${ }^{6}$

- Health behaviors index 4 (behaviors that impacts others moderately and me strongly): not touching the face and washing hands.

To aggregate the individual items into each index, we standardize each item (subtract the mean and then divide it by the standard deviation), add the items, divide the result by the number of items, and standardize the index again such that effect sizes are comparable across indices.

We also measure the following behaviors:

- Buys a cloth face mask: Subjects have to choose between $\$ 20$ or a cloth face mask that has a value of $\$ 25 .^{7}$ We incentivize this question by implementing the choice of 10 randomly drawn participants.

- Information seeking: At the end of the survey, participants are presented with links where they can learn more about how to protect themselves and others and how to support the healthcare system. We record whether participants click on the links. Links are presented to participants once the questionnaire is over and are likely not perceived as being part of the study.

- Donation to COVID-19 fund: Subjects receive $\$ 20$ and can donate up to $\$ 10$ to a solidarity response fund by the World Health Organization and UNICEF to fight COVID19. We incentivize this question by implementing the choice of 10 randomly drawn participants.

\footnotetext{
${ }^{6}$ Furthermore, we ask the same questions for "a regular week in April last year." As preregistered, for this index we control for the past behavior when analyzing current behavior. When we create the index, we invert the scales of all three items such that higher values corresponds to higher levels of social responsibility, as in the other measures.

${ }^{7}$ We opted for cloth face masks because studies suggest that they can be effective in protecting others, but that they are not particularly effective for self-protection (Davies et al., 2013; ECDPC, 2020). This might make them relatively more attractive for prosocial people. Moreover, cloth face masks are not used by healthcare workers. This means that participants need not be worried about effective allocation of these masks. We mention all of this to subjects when they make their choice (see Appendix Section D).
} 
We preregistered health behaviors index 1 as the main outcome variable of this study and the six other measures as the secondary outcome variables. Appendix Section A gives the distributions of the behavioral measures and shows that the two sets of health behaviors correlate strongly.

We also ask about sociodemographics, including age, gender, income, occupation, and household characteristics. In addition, we ask about their perceptions and beliefs regarding COVID-19 and whether they have masks at home. Participants also do a hypothetical choice experiment on self-quarantining for another research project that is not part of this study (as preregistered in our analysis plan). Finally, we include a battery of questions about their confidence in the government, math skills, rule-following as well as self-reported risk preferences, time preferences, trust, and the two survey questions on prosociality (prosociality GPS) (Falk et al., 2018).

Previous social preferences survey in 2018. We link to our current survey an older measure of Prosociality GPS (as described above) collected in 2018.

Specification. As preregistered, we estimate the effect of social preferences on health behaviors using OLS as follows:

$$
\text { HealthBehavior }_{i}=\beta_{0}+\beta_{1} \text { Prosociality }_{i}+X_{i}^{\prime} \delta+\varepsilon_{i}
$$

The dependent variable is HealthBehavior ${ }_{i}$, which captures one of the seven health behavior variables. The coefficient of interest is $\beta_{1}$ for the effect of prosociality on health behaviors. Controls are captured by $X_{i}^{\prime}$. We preregistered age and gender as the controls for our main specification, but we show results with more comprehensive controls as well. ${ }^{8}$ As pre-registered, the reported p-values are based on one-sided tests.

\section{Results}

Social preferences: willingness to put others at risk. A large share of people are very averse to putting others at risk. Figure 1 displays the risk that dictators put on the

\footnotetext{
${ }^{8}$ For the health behavior index 3 , we control for the same behaviors around the same time last year as preregistered.
} 
Figure 1: Distribution of choices capturing prosociality
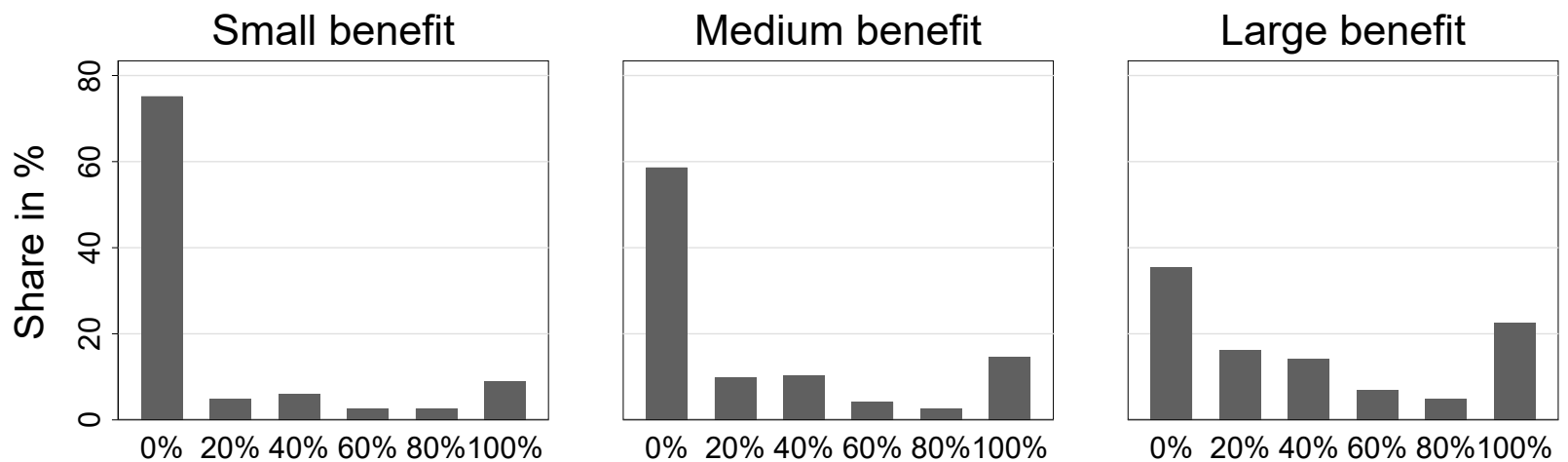

Risk put on the other person

Note: This table reports participants' decisions in three of the five Risk Dictator Games that they played. In the Risk Dictator Game, a dictator chooses with what risk $(0 \%, 20 \%, 40 \%, 60 \%, 80 \%$, or $100 \%$ ) a recipient loses his/her endowment of $\$ 10$. Putting higher risk on the recipient increases the payoff of the dictator. In the small benefit game, dictators receive $\$ 0.5$ for each additional $20 \%$ risk they put on the recipient. In the medium benefit game, they receive $\$ 2$ for each additional $20 \%$ risk. In the large benefit game, they receive $\$ 10$ for each additional $20 \%$ risk. Appendix Figure A.1 shows the distribution for the two other games, in which the dictator increases his/her payoff by an additional $\$ 1$ (small-medium benefit) and $\$ 5$ (medium-large benefit) for each additional $20 \%$ risk.

other participant, the recipient. The first panel shows the choices for the game where risking the recipient's money comes with a small benefit of $\$ 0.5$ for each additional $20 \%$ risk. The second and third panels show the choices for games with a medium benefit of $\$ 2$ and a large benefit of $\$ 10$ for each additional $20 \%$ risk. In the game with the small benefit, over $70 \%$ of participants do not put others at risk. Even in the game where the gains of exposing the recipient's money are large, $34 \%$ of the participants refrain from exposing others to risk.

Across all five games, recipients are only exposed to a median risk of $16 \%$. One third of all participants never expose the recipient to any risk in any of the five games. This means that they always choose $0 \%$ risk, even when the benefits of putting others at risk are large. However, there is substantial heterogeneity in peoples' prosociality; for example, $7 \%$ of the participants sacrifice the other participant's money even for small gains.

The fact that our participants are very averse to exposing others to risk for their personal benefit suggests that people care about the social impact of their behavior. However, these results do not imply that people consider the social impact that their health behavior has for others. To test whether the prosociality that we capture in the experiment translates into behavior in the health domain, we study whether differences in the willingness to put others at risk explain people's different health behaviors. We construct the measure of prosociality 
Figure 2: Prosociality predicts health behaviors

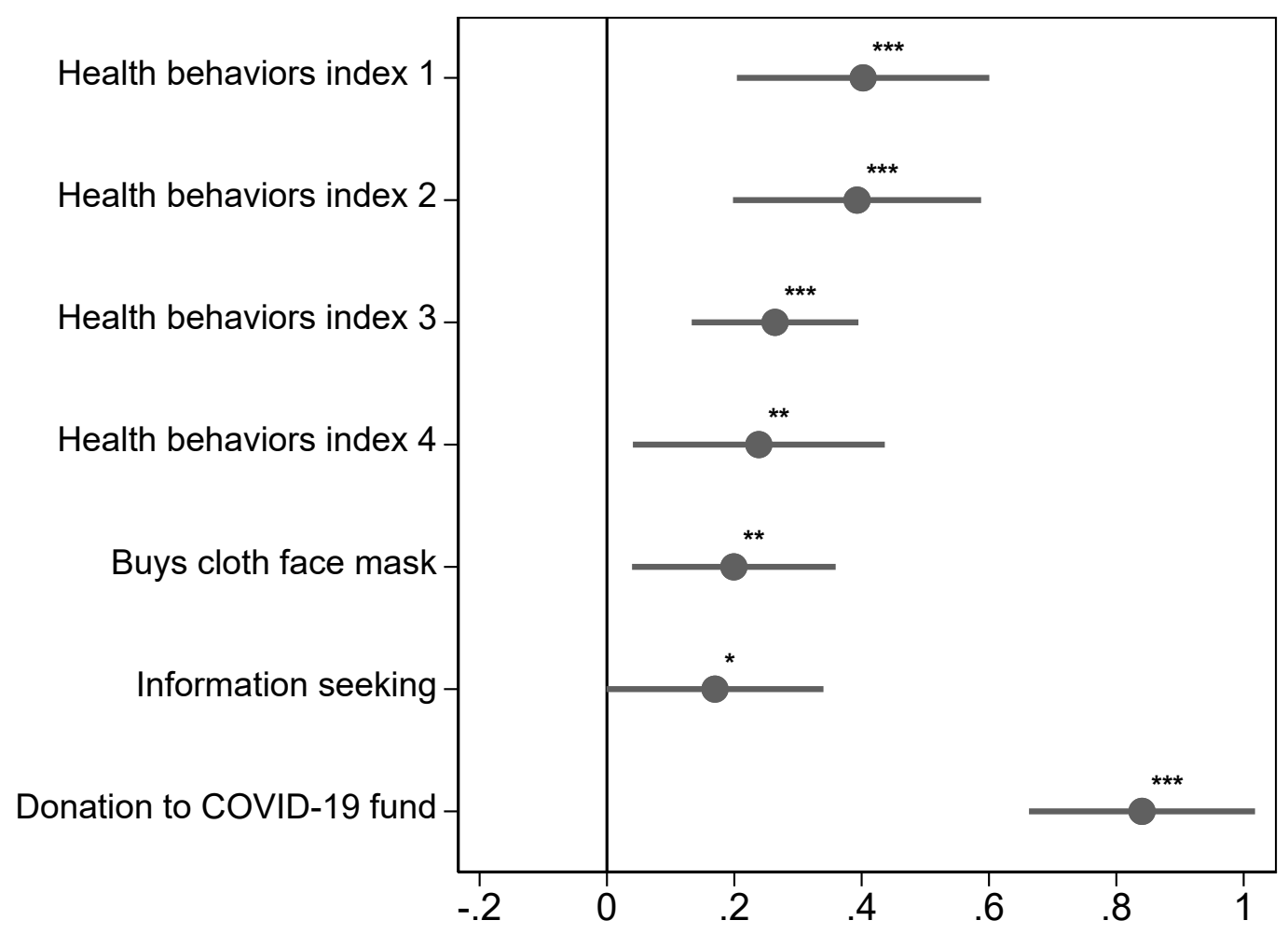

Note: The figure shows coefficient estimates from a linear regression of the outcome variable (shown on the left) on prosociality, controlling for age and gender (preregistered specification). The coefficient estimates give the change in the outcome variables in standard deviations when moving from least prosocial $(=0)$ to most prosocial $(=1)$. Prosociality is measured by an incentivized experimental method where people can expose others to risks in return for a higher payment for themselves. The figure also shows standard errors bars corresponding to a two-sided significance test at the 10\%-level. The comparison against 0 corresponds to a one-sided significance test at the 5\%-level, as preregistered.

We build the first four outcome variables based on thirteen self-reported health behaviors during the COVID-19 pandemic, exactly as preregistered and as described in Appendix Table A.1. To build the indices, we measured the perceptions of an independent sample of 100 Swedes on whether each health behavior protects others and oneself. We then grouped them in the following four categories: 1) Health behaviors index 1 (perceived to impact others strongly, and oneself moderately). Consists of: self-isolates if symptoms, coughs and sneezes into the elbow, informs others if symptoms, wears mask if symptoms. 2) Health behaviors index 2 (perceived to impact others strongly, and oneself strongly). Consists of: avoids social contacts, informs oneself, keeps at least two meters distance, refrains from private domestic trips. 3) Health behaviors index 3 (perceived to impact others strongly, and oneself strongly). Consists of: avoids leaving the house to buy things other than food and drugs, avoids doing physical activities with other people, avoids hanging out with friends and relatives. 4) Health behaviors index 4 (perceived to impact others moderately, and oneself strongly). Consists of: avoids touching the face, washes hands regularly. The remaining three outcome variables are: 5) Buys cloth face mask: whether the participant chooses a cloth face mask (that mostly protects others) over \$20 6) Information seeking: number of clicks to websites with information about how to help and protect others. 7) Donation to COVID-19 fund: Donation amount to a COVID-19 solidarity fund by the WHO and UNICEF. ${ }^{*} p<0.10,{ }^{* *} p<0.05,{ }^{* * *} p<0.01$

as one minus the average risk each participant puts on other participants across all five games (Appendix Figure A.2 shows the distribution of this measure). 
Social preferences predict health behaviors. Figure 2 shows that prosociality predicts how people behave in reaction to the COVID-19 pandemic, controlling for age and gender (preregistered specification). ${ }^{9}$ We see substantial and statistically significant effects for the four indices of health behaviors. The effects are largest for behaviors that impact others strongly captured by health behaviors index 1 to $3(p<0.01)$. Moving from a minimal prosociality of 0 to a maximal prosociality of 1 improves these behaviors by around 0.3 to 0.4 of a standard deviation (see Table 2 for the coefficient estimates). We also see substantial effects for behaviors that impact others moderately as captured by health behaviors index $4(\beta=0.24, p<0.05)$. When we regress each of the 13 behaviors underlying the indices separately on prosociality, all coefficients are positive and ten are statistically significant at the 5\%-level (see Appendix Figure B.3).

Figure 2 also shows the estimates for the three measures of behaviors that fight COVID19 within our survey. People who are more prosocial are more likely to buy a cloth face mask $(\beta=0.20, p<0.05)$ and to donate a higher amount to a fund for the fight against COVID-19 $(\beta=0.84, p<0.01)$. Moreover, we see a positive link between prosociality and clicking links to websites where one can get more information on how to help and protect others during the COVID-19 pandemic, although this relation is only marginally significant $(\beta=0.14, p<0.1)$. Taken together, the results show a clear pattern: more prosocial people have better health behaviors than less prosocial people during the COVID-19 pandemic.

Considering risk and time preferences, health, worries, and personality. Table 2 shows that prosociality predicts health behaviors controlling for additional sociodemographics, risk and time preferences, worries about being infected, health, personality, and trust. The coefficients remain stable for all outcomes across the specifications.

Specification (1) shows the preregistered specification that controls for age and gender. The coefficient estimates correspond to the estimates visualized in Figure 2. The effects are largest for indices 1 to 3 that capture behaviors that impact others strongly $(p<0.01)$ as well as for donations to the COVID-19 fund $(p<0.01)$.

In specification (2), we add sociodemographics as well as response date and county fixed effects. In specifications (3) to (5), we take into account controls that capture selfish motiva-

\footnotetext{
${ }^{9}$ Appendix Figures A.4-A.8 give the raw distributions of the behaviors. Appendix Figure B.1 shows scatterplots for all outcomes.
} 


\section{Table 2: Prosociality predicts health behaviors controlling for other preferences, worries, health, and personality}

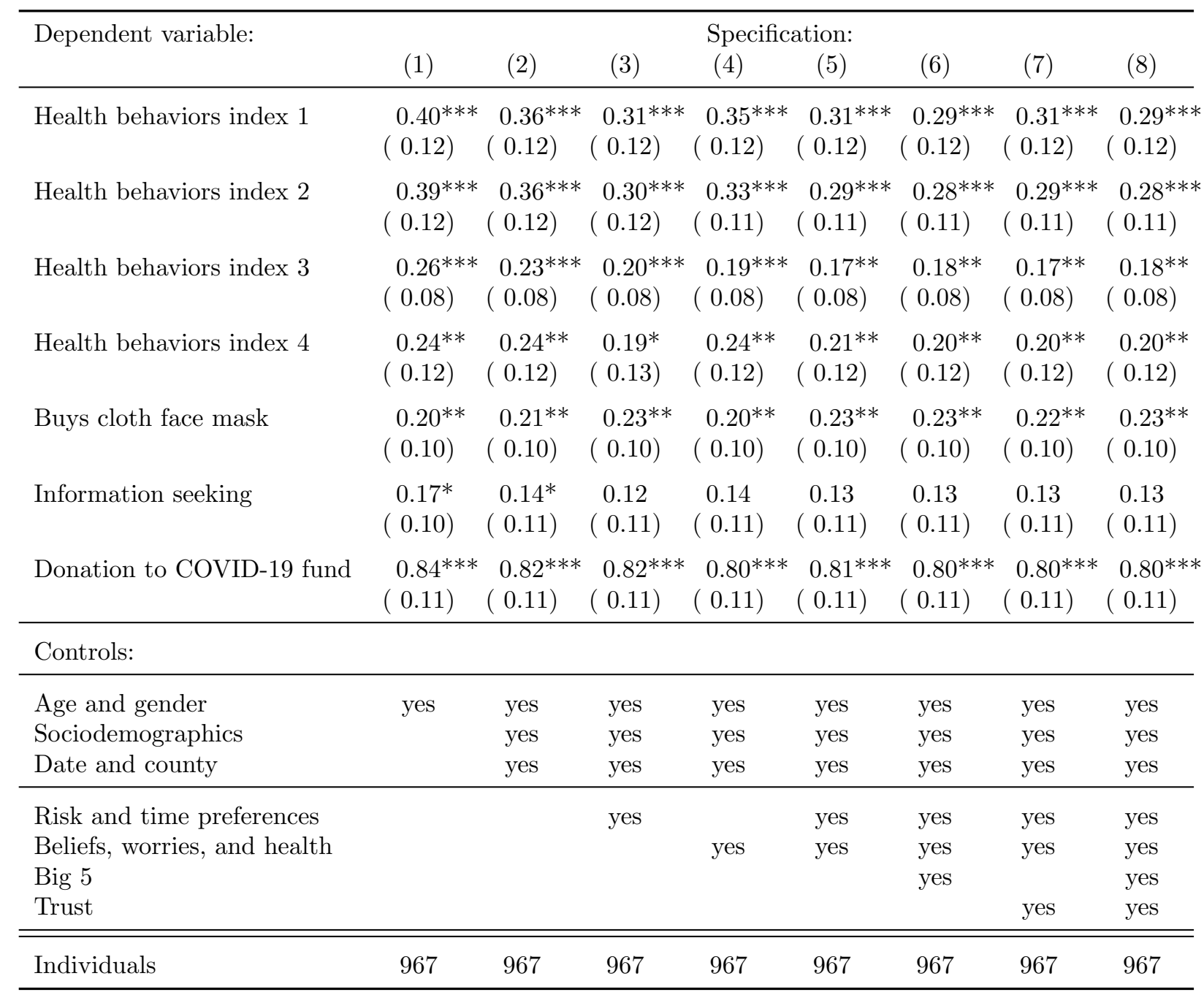

Note: The table shows coefficient estimates from linear regressions of the outcome variable (shown on the left and described in Figure 2) on prosociality. Heteroscedasticity robust standard errors are shown in parentheses. Sociodemographics include dummies for all education, number of children, household income, occupation, and marital status categories (see Appendix Table C.2 for all categories). Date and county refers to including categorical dummies for counties and response dates. In addition, regressions (3) and (5)(8) also control for participants' risk aversion, beliefs about others' risk aversion, and patience. Regressions (4)-(8) control for participants' life expectancy (a proxy of their health) and whether participants worry about getting infected, that the healthcare will not be able to offer good care to everyone, that their finances will be hit hard, and that the Swedish economy will be hit hard. Regressions (6) and (8) control for the Big Five traits and regressions (7)-(8) for trust. As preregistered, $p$-values are based on one-sided tests.

* $p<0.10,{ }^{* *} p<0.05$, *** $p<0.01$ 
tions. These are: risk and time preferences (3), as measured by an incentivized task (Gneezy and Potters, 1997) and by an experimentally validated survey question (Falk et al., 2018); beliefs and worries about being infected and life expectancy as a proxy for health (4); and all these together (5). While risk and time preferences, as well as worries, seem to explain a small part of the effects, the coefficients remain remarkably stable with the inclusion of additional predictors of behavior.

In specifications (6) to (8), we control for personality as captured by a measure of each of the Big Five personality traits (Gosling, Rentfrow and Swann, 2003) and trust as captured by an experimentally validated survey question (Falk et al., 2018). Clearly, both the traits agreeableness and trust are linked to prosociality and could well capture a similar factor. This implies that we are most likely overcontrolling in these specifications, in the sense that we might absorb part of the effect that we aim to measure. The results indicate that personality and trust do not account for our results, as the coefficients change little when we include these measures. Additional sensitivity checks suggests that adding a higher number or more comprehensive proxies for individual characteristics is unlikely to substantially alter the results (see Appendix Table B.3).

Previous research has shown that risk preferences are important drivers of health behaviors (Anderson and Mellor, 2008; Dohmen et al., 2011; Galizzi and Wiesen, 2018). Hence, comparing the estimates for prosociality with the estimates for risk preferences allows us to better understand the relevance of social preferences. Across all outcomes, we find that the effect of moving from minimal to maximal prosociality is larger than when moving from minimal to maximal risk aversion. For example, the coefficient for the health behaviors index 1 is $0.4(p<0.01)$ for prosociality and $0.24(p<0.05)$ for risk aversion. In this case, the effect of prosociality is more than 1.5 times larger than the effect of risk aversion.

Taken together, the results: i) are robust to including additional sociodemographics, ii) cannot be explained by more traditional predictors of health behaviors, such as time and risk preferences or worries about getting infected, and iii) predict behaviors above and beyond personality and trust.

Prosociality two years before the pandemic and other measures. Figure 3 replicates Figure 2 using an alternative unincentivized prosociality measure. The measure is based on an experimentally validated survey measure from the Global Preference Survey (GPS) (Falk 
Figure 3: A second measure of prosociality collected in 2020 and in 2018 predicts health behaviors

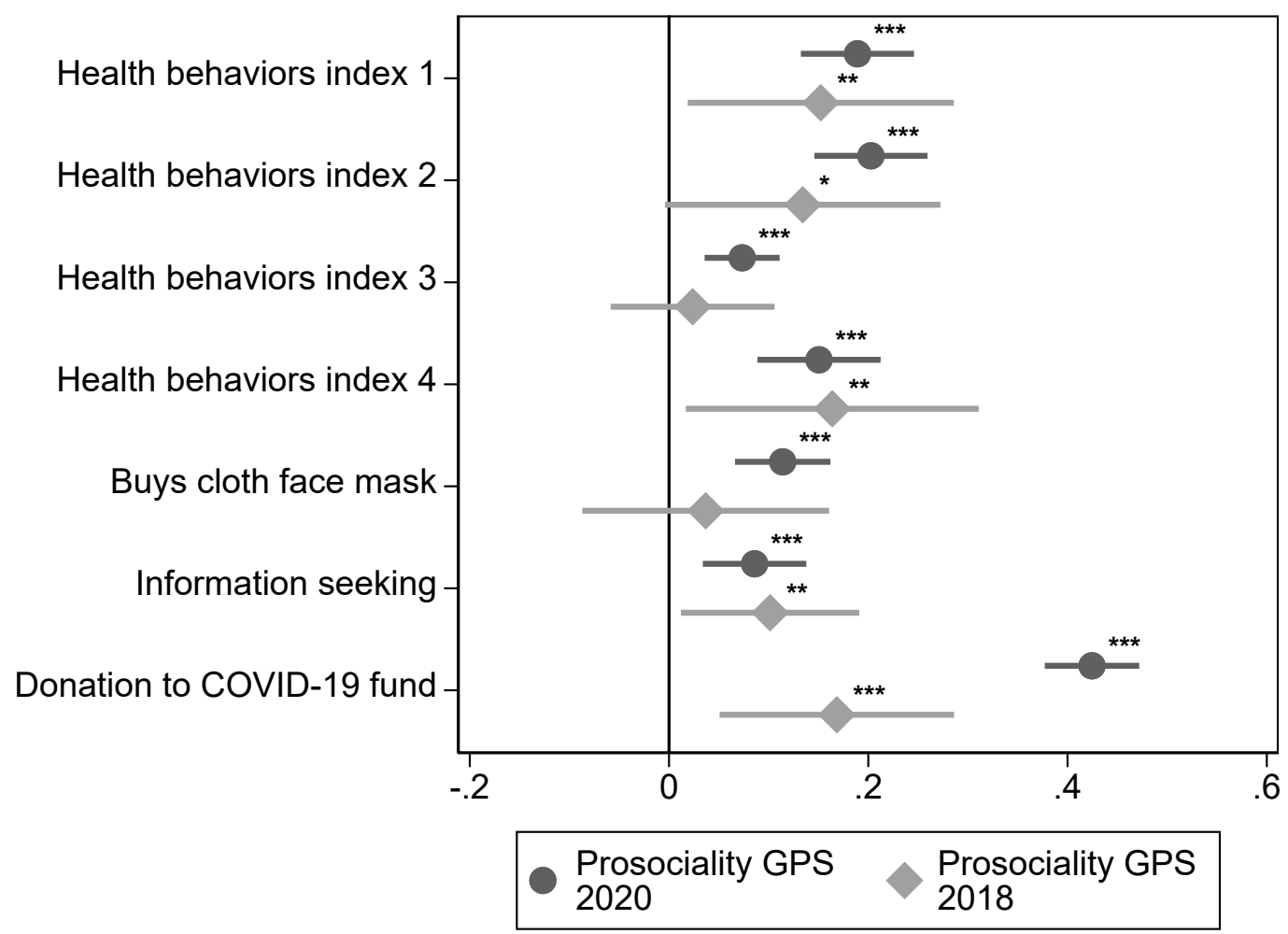

Note: The figure shows coefficient estimates from a linear regression of the outcome variable (shown on the left) on prosociality, controlling for age and gender (preregistered specification). The figure replicates Figure 2 using a second measure of prosociality. Prosociality is captured by an experimentally validated question on people's willingness to give to a good cause without expecting anything in return used in the Global Preference Survey. We use this measure in the current social preferences survey (Prosociality GPS 2020) and for a subset of 197 participants in 2018 (Prosociality GPS 2018). ${ }^{*} p<0.10,{ }^{* *} p<0.05,{ }^{* * *} p<0.01$ 
et al., 2018). We capture it in the current social preferences survey (denoted Prosociality GPS 2020) and in a survey answered by a subset of the participants in 2018 (denoted Prosociality GPS 2018).

The results using the alternative measure of prosociality collected in the current survey, Prosociality GPS 2020, resemble our main results. We see substantial effects for all behavior indices as well as for buying a cloth face mask, seeking information, and donating for the fight against COVID-19. These effects are all statistically precisely estimated $(p<0.01)$. Consistent with the similar pattern, we observe strong correlations between the different prosociality measures (see Appendix Figure A.3). In the Appendix, we provide further results using these measures (Appendix Table B.1 and Table B.2, as well as Figure B.2). Once again, the results show that higher prosociality goes together with better health behavior during the COVID-19 pandemic.

We also explore whether prosociality measured two years before the pandemic predicts health behaviors during the pandemic. Given the much smaller sample size, these coefficients are estimated less precisely. But again, we find a clear pattern indicating that more prosocial people in 2018 show better health behaviors in 2020. Across all outcomes, the coefficients for Prosociality GPS 2018 are positive, meaning that respondents who are more prosocial behave more responsibly. The coefficient estimates are particularly large and precisely estimated for the health behavior index $1(p<0.01)$, health behaviors index $4(p<0.05)$, information seeking $(p<0.05)$, and donations for the fight against COVID-19 $(p<0.01)$ (see also Appendix Table B.2).

The additional results underscore the robustness of our findings by showing that i) an

alternative measure of prosociality is strongly predictive of health behaviors, ii) a measure of prosociality collected two years before the pandemic yields positive and qualitatively similar estimates, which implies that prosociality is predictive of health behaviors in the long-run, and iii) our results are not driven by a change in preferences due to the COVID-19 outbreak.

\section{Conclusion}

Many governments around the world have implemented harsh measures to limit public life at the peak of the COVID-19 pandemic. Such stringent restrictions are likely to be the most successful in preventing the spread of the disease, but they also have substantial short-run 
social and economic costs (Cao et al., 2020; Friedman et al., 2020; Holmes et al., 2020; Taub Amanda, 2020). National and regional governments are thus devising and implementing plans to reopen public life, though the risks associated with such relaxation of restrictions rest critically on whether a population voluntarily takes into account the social impact of their health behaviors. If people completely neglect the social impact of their behaviors, there is a higher need for extreme and lasting restrictions. However, if people voluntarily consider the social impact of their behavior, a notion generally omitted from models of disease spread, countries might be able to partly replace restrictions with recommendations.

Our results indicate that people do consider the social impact of their behavior during a pandemic. In incentivized studies, we first document that many participants avoid putting others at risk even when the benefit from doing so is large. We then show that such prosociality predicts health behaviors that are important for reducing the spread of an infection. More prosocial people are more likely to follow physical distancing and hygiene recommendations, inform themselves about how they can help others, donate to fighting COVID-19, and buy a cloth face mask. We also document a positive relationship between prosociality measured two years before the pandemic and better health behaviors in response to COVID19. Taken together, the results reveal that prosociality is an essential and stable determinant of important policy-relevant behaviors.

While the focus on the COVID-19 pandemic allows us to inform policy makers and scientists during this and other pandemics, a natural question is how easily our findings generalize to other health behaviors outside of the current context. Many behaviors impact the health of other people, such as smoking in a public place, getting a flu vaccine, and drunk driving. While economic models of health behaviors rest on the assumption that individuals act selfishly (Grossman, 1972; Becker and Murphy, 1988; Bernheim and Rangel, 2004), it seems likely that incorporating prosocial motives could help us to better understand these behaviors. It is important to note that our Risk Dictator Game does not involve any framing that is specifically linked to COVID-19, but instead measures a general willingness to forgo personal benefit to mitigate risks to others - a tradeoff common to many important healthrelated behaviors. Nevertheless, given that we cannot directly speak to the precise motives for the wide variety of such behaviors, we hope that further research will analyze the role of prosociality in other contexts. Additional insights into whether prosociality can predict these behaviors may also inform public health policy in more normal times. 
The academic implications of our findings are closely tied to their policy implications. Models of disease spread that are used for evaluating policy scenarios may be enriched by incorporating prosocial motives. Previous work reveals substantial heterogeneity in prosociality across regions (Falk et al., 2018; WGI, 2018; Herrmann, Thöni and Gächter, 2008; Almås, Cappelen and Tungodden, 2020), and public health policy could benefit from considering such regional differences. With this information, governments could adapt the speed and the way in which they lift restrictions in accordance with the degree of prosociality in the population. Nations and regions with higher prosociality might face relatively less severe public health consequences when replacing rules with recommendations. 


\section{References}

Almås, Ingvild, Alexander W. Cappelen, and Bertil Tungodden. 2020. "Cutthroat capitalism versus cuddly Socialism: Are Americans more meritocratic and efficiency-seeking than Scandinavians?" Journal of Political Economy, forthcoming.

Almås, Ingvild, Alexander W. Cappelen, Erik Sørensen, and Bertil Tungodden. 2010. "Fairness and the development of inequality acceptance." Science, 328(5982): 1176-1178.

Anderson, Lisa R., and Jennifer M. Mellor. 2008. "Predicting health behaviors with an experimental measure of risk preference." Journal of Health Economics, 27(5): 1260-1274.

Andersson, Ola, Håkan J. Holm, Jean-Robert Tyran, and Erik Wengström. 2020. "Risking other people's money: Experimental evidence on the role of incentives and personality traits." The Scandinavian Journal of Economics, 122(2): 648-674.

Andreoni, James, and John Miller. 2002. "Giving According to GARP: An Experimental Test of the Consistency of Preferences for Altruism." Econometrica, 70(2): 737-753.

Bai, Liang, Benjamin Handel, Edward Miguel, and Gautam Rao. 2017. "Self-control and demand for preventive health: Evidence from hypertension in india." NBER WP No. 23727.

Bartling, Björn, Roberto A. Weber, and Lan Yao. 2015. "Do markets erode social responsibility?" The Quarterly Journal of Economics, 130(1): 219-266.

Bavel, Jay J. Van, Katherine Baicker, Paulo S. Boggio, Valerio Capraro, Aleksandra Cichocka, Mina Cikara, Molly J. Crockett, Alia J. Crum, Karen M. Douglas, James N. Druckman, John Drury, Oeindrila Dube, Naomi Ellemers, Eli J. Finkel, James H. Fowler, Michele Gelfand, Shihui Han, S. Alexander Haslam, Jolanda Jetten, Shinobu Kitayama, Dean Mobbs, Lucy E. Napper, Dominic J. Packer, Gordon Pennycook, Ellen Peters, Richard E. Petty, David G. Rand, Stephen D. Reicher, Simone Schnall, Azim Shariff, Linda J. Skitka, Sandra Susan Smith, Cass R. Sunstein, Nassim Tabri, Joshua A. Tucker, Sander van der Linden, Paul van Lange, Kim A. Weeden, Michael J. A. Wohl, Jamil Zaki, Sean R. Zion, and Robb Willer. 2020. "Using social and behavioural science to support COVID-19 pandemic response." Nature Human Behaviour, 1-12.

Becker, Gary S., and Kevin M. Murphy. 1988. "A theory of rational addiction." Journal of Political Economy, 96(4): 675-700.

Bernheim, B. Douglas, and Antonio Rangel. 2004. "Addiction and cue-triggered decision processes." American Economic Review, 94(5): 1558-1590.

Bethune, Zachary, and Anton Korinek. 2020. "Covid-19 infection externalities: Trading off lives vs. livelihoods." NBER WP No. 27009.

Betsch, Cornelia, Robert Böhm, Lars Korn, and Cindy Holtmann. 2017. "On the benefits of explaining herd immunity in vaccine advocacy." Nature Human Behaviour, 1(3): 1-6.

Bogg, Tim, and Brent W. Roberts. 2004. "Conscientiousness and health-related behaviors: A meta-analysis of the leading behavioral contributors to mortality." Psychological Bulletin, 130(6): 887-919.

Bogg, Tim, and Brent W. Roberts. 2013. "The case for conscientiousness: Evidence and implications for a personality trait marker of health and longevity." Annals of Behavioral Medicine, 45(3): 278-288.

Bolton, Gary E., and Axel Ockenfels. 2000. "ERC: A theory of equity, reciprocity, and competition." American Economic Review, 90(1): 166-193.

Booth-Kewley, Stephanie, and Ross R. Vickers. 1994. "Associations between major domains of personality and health behavior." Journal of Personality, 62(3): 281-298. 
Branas-Garza, Pablo, Diego Andrés Jorrat, Antonio Alfonso, Antonio M. Espin, Teresa García, and Jaromir Kovarik. 2020. "Exposure to the Covid-19 pandemic and generosity in southern Spain." PsyArXiv preprint.

Brewer, Noel T., Gretchen B. Chapman, Alexander J. Rothman, Julie Leask, and Allison Kempe. 2017. "Increasing vaccination: Putting psychological science into action." Psychological Science in the Public Interest, 18(3): 149-207.

Briscese, Guglielmo, Nicola Lacetera, Mario Macis, and Mirco Tonin. 2020. "Compliance with COVID-19 social-distancing measures in italy: The role of expectations and duration." NBER WP 26916.

Brock, J. Michelle, Andreas Lange, and Erkut Y. Ozbay. 2013. "Dictating the risk: Experimental evidence on giving in risky environments." American Economic Review, 103(1): 415-437.

Cao, Wenjun, Ziwei Fang, Guoqiang Hou, Mei Han, Xinrong Xu, Jiaxin Dong, and Jianzhong Zheng. 2020. "The psychological impact of the COVID-19 epidemic on college students in China." Psychiatry Research, 287: 112934.

Cawley, John, and Christopher J. Ruhm. 2011. "The economics of risky health behaviors." In Handbook of Health Economics. Vol. 2, 95-199. Elsevier B.V.

Chabris, Christopher F., David Laibson, Carrie L. Morris, Jonathon P. Schuldt, and Dmitry Taubinsky. 2008. "Individual laboratory-measured discount rates predict field behavior." Journal of Risk and Uncertainty, 37(2-3): 237-269.

Chapman, Gretchen B., and Elliot J. Coups. 1999. "Time preferences and preventive health behavior." Medical Decision Making, 19(3): 307-314.

Charness, G., and M. Rabin. 2002. "Understanding social preferences with simple tests." The Quarterly Journal of Economics, 117(3): 817-869.

Chen, M. Keith. 2013. "The effect of language on economic behavior: Evidence from savings rates, health behaviors, and retirement assets." American Economic Review, 103(2): 690731.

Chesson, Harrell W., Jami S. Leichliter, Gregory D. Zimet, Susan L. Rosenthal, David I. Bernstein, and Kenneth H. Fife. 2006. "Discount rates and risky sexual behaviors among teenagers and young adults." Journal of Risk and Uncertainty, 32(3): 217-230.

Crockett, Molly J., Luke Clark, Marc D. Hauser, and Trevor W. Robbins. 2010. "Serotonin selectively influences moral judgment and behavior through effects on harm aversion." Proceedings of the National Academy of Sciences of the United States of America, 107(40): 17433-17438.

Davies, Anna, Katy Anne Thompson, Karthika Giri, George Kafatos, Jimmy Walker, and Allan Bennett. 2013. "Testing the efficacy of homemade masks: would they protect in an influenza pandemic?" Disaster medicine and public health preparedness, 7(4): 413-418.

Dawes, Christopher T., James H. Fowler, Tim Johnson, Richard McElreath, and Oleg Smirnov. 2007. "Egalitarian motives in humans." Nature, 446(7137): 794-796.

DellaVigna, Stefano, and Ulrike Malmendier. 2006. "Paying not to go to the gym." American Economic Review, 96(3): 694-719.

De Quidt, Jonathan, Johannes Haushofer, and Christopher Roth. 2018. "Measuring and bounding experimenter demand." American Economic Review, 108(11): 3266-3302.

Dohmen, Thomas, Armin Falk, David Huffman, Uwe Sunde, Jürgen Schupp, and Gert G. Wagner. 2011. "Individual risk attitudes: Measurement, determinants, and behavioral consequences." Journal of the European Economic Association, 9(3): 522-550. 
ECDPC. 2020. "Using face masks in the community - Reducing COVID-19 transmission from potentially asymptomatic or pre-symptomatic people through the use of face masks."

Eichenbaum, Martin, Sergio Rebelo, and Mathias Trabandt. 2020. "The macroeconomics of epidemics." NBER WP No. 26882.

Epper, Thomas, Ernst Fehr, and Julien Senn. 2020. "Other-regarding preferences and redistributive politics." UZH WP No. 339.

Everett, Jim AC, Clara Colombatto, Vladimir Chituc, William J. Brady, and Molly Crockett. 2020. "The effectiveness of moral messages on public health behavioral intentions during the COVID-19 pandemic." PsyArXiv.

Exley, Christine L. 2016. "Excusing selfishness in charitable giving: The role of risk." The Review of Economic Studies, 83(2): 587-628.

Falk, Armin, Anke Becker, Thomas Dohmen, Benjamin Enke, David Huffman, and Uwe Sunde. 2018. "Global Evidence on Economic Preferences." Quarterly Journal of Economics, 133(4): 1645-1692.

Fang, Yaqing, Yiting Nie, and Marshare Penny. 2020. "Transmission dynamics of the COVID19 outbreak and effectiveness of government interventions: A data-driven analysis." Journal of Medical Virology, 92(6): 645-659.

Farboodi, Maryam, Gregor Jarosch, and Robert Shimer. 2020. "Internal and external effects of social distancing in a pandemic." NBER WP No. 27059.

Fehr, E., and K. M. Schmidt. 1999. "A theory of fairness, competition, and cooperation." Quarterly Journal of Economics, 114(3): 817-868.

Fehr, Ernst, and Simon Gächter. 2002. "Altruistic punishment in humans." Nature, 415(6868): 137-140.

Fisman, Raymond, Pamela Jakiela, and Shachar Kariv. 2017. "Distributional preferences and political behavior." Journal of Public Economics, 155: 1-10.

Fisman, R., P. Jakiela, S. Kariv, and D. Markovits. 2015. "The distributional preferences of an elite." Science, 349(6254): aab0096-aab0096.

Freundt, Jana, and Andreas Lange. 2017. "On the determinants of giving under risk." Journal of Economic Behavior and Organization, 142: 24-31.

Friedman, Eric, John Friedman, Simon Johnson, and Adam Landsberg. 2020. "Transitioning out of the coronavirus lockdown: A framework for zone-based social distancing." arXiv:2004.08504.

Friedman, Howard S., and Margaret L. Kern. 2014. "Personality, well-being, and health." Annual Review of Psychology, 65(1): 719-742.

Gächter, Simon, Felix Kölle, and Simone Quercia. 2017. "Reciprocity and the tragedies of maintaining and providing the commons." Nature Human Behaviour, 1(9): 650-656.

Galizzi, Matteo M., and Daniel Wiesen. 2018. "Behavioral experiments in health economics." In Oxford Research Encyclopedia of Economics and Finance. Ed.: Jonathan H. Hamilton, Avinash Dixit, Sebastian Edwards and Kenneth Judd.

Galizzi, Matteo M., Sara R. Machado, and Raffaele Miniaci. 2016. "Temporal stability, crossvalidity, and external validity of risk preferences measures: Experimental evidence from a UK Representative sample." Mimeo, London School of Economics.

Garibaldi, Pietro, Espen R. Moen, and Christopher A. Pissarides. 2020. "Search and matching." Covid Economics: Vetted and Real-Time Papers, -(5):--. 
Gneezy, U., and J. Potters. 1997. "An experiment on risk taking and evaluation periods." Quarterly Journal of Economics, 112(2): 631-645.

Gosling, Samuel D., Peter J. Rentfrow, and William B. Swann. 2003. "A very brief measure of the Big-Five personality domains." Journal of Research in Personality, 37(6): 504-528.

Grant, Adam M, and David A Hofmann. 2011. "It's not all about me: motivating hand hygiene among health care professionals by focusing on patients." Psychological Science, 22(12): 1494-9.

Grossman, Michael. 1972. The demand for health: A theoretical and empirical investigation. NBER.

Haisley, Emily C., and Roberto A. Weber. 2010. "Self-serving interpretations of ambiguity in other-regarding behavior." Games and Economic Behavior, 68(2): 614-625.

Hardardottir, Hjördis, Ulf-G. Gerdtham, and Erik Wengström. 2019. "What kind of inequality do you prefer? Evaluating measures of income and health inequality using choice experiments." Lund University WP 2019:7.

Harrison, Glenn W., Morten I. Lau, and E. Elisabet Rutström. 2010. "Individual discount rates and smoking: Evidence from a field experiment in Denmark." Journal of Health Economics, 29(5): 708-717.

Hauser, Oliver P., David G. Rand, Alexander Peysakhovich, and Martin A. Nowak. 2014. "Cooperating with the future." Nature, 511(7508): 220-223.

Haushofer, Johannes, Anett John, and Kate Orkin. 2019. "Can simple psychological interventions increase preventive health investment?" NBER WP No. 25731.

Henrich, Joseph, Robert Boyd, Samuel Bowles, Colin Camerer, Ernst Fehr, Herbert Gintis, Richard McElreath, Michael Alvard, Abigail Barr, Jean Ensminger, Natalie Smith Henrich, Kim Hill, Francisco Gil-White, Michael Gurven, Frank W. Marlowe, John Q. Patton, and David Tracer. 2005. "Economic man" in cross-cultural perspective: Behavioral experiments in 15 small-scale societies." Behavioral and Brain Sciences, 28(6): 795-815.

Herrmann, Benedikt, Christian Thöni, and Simon Gächter. 2008. "Antisocial punishment across societies." Science, 319(5868): 1362-1367.

Hershey, John C., David A. Asch, Thi Thumasathit, Jacqueline Meszaros, and Victor V. Waters. 1994. "The roles of altruism, free riding, and bandwagoning in vaccination decisions." Organizational Behavior and Human Decision Processes, 59(2): 177-187.

Holmes, Emily A, Rory C O'connor, Hugh Perry, Irene Tracey, Simon Wessely, Louise Arseneault, Clive Ballard, Helen Christensen, Roxane Cohen Silver, Ian Everall, Tamsin Ford, Ann John, Thomas Kabir, Kate King, Ira Madan, Susan Michie, Andrew K Przybylski, Roz Shafran, Angela Sweeney, Carol M Worthman, Lucy Yardley, Katherine Cowan, Claire Cope, Matthew Hotopf, and Ed Bullmore. 2020. "Multidisciplinary research priorities for the COVID-19 pandemic: a call for action for mental health science." The Lancet Psychiatry, online.

Ibuka, Yoko, Meng Li, Jeffrey Vietri, Gretchen B Chapman, and Alison P Galvani. 2014. "Free-riding behavior in vaccination decisions: An experimental study." PLOS ONE, 9(3): e94066.

Ingledew, David K., and Stuart Brunning. 1999. "Personality, preventive health behaviour and comparative optimism about health problems." Journal of Health Psychology, 4(2): 193-208.

Jordan, Jillian, Erez Yoeli, and David Rand. 2020. "Don't get it or don't spread it? Comparing self-interested versus prosocially framed COVID-19 prevention messaging." PsyArXiv. 
Kermack, William O., and A. G. McKendrick. 1927. "A contribution to the mathematical theory of epidemics." Proceedings of the Royal Society of London. Series A, Containing Papers of a Mathematical and Physical Character, 115(772): 700-721.

Kern, Margaret L., and Howard S. Friedman. 2008. "Do conscientious individuals live longer? A quantitative review." Health Psychology, 27(5): 505-512.

Krawczyk, Michal, and Fabrice Le Lec. 2010. “'Give me a chance!' An experiment in social decision under risk." Experimental Economics, 13(4): 500-511.

Krueger, Dirk, Harald Uhlig, and Taojun Xie. 2020. "A theory of the "Swedish solution"." Covid Economics: Vetted and Real-Time Papers, -(5):--

Lergetporer, Philipp, Silvia Angerer, Daniela Glätzle-Rützler, and Matthias Sutter. 2014. "Third-party punishment increases cooperation in children through (misaligned) expectations and conditional cooperation." Proceedings of the National Academy of Sciences of the United States of America, 111(19): 6916-6921.

Li, Meng, Eric G Taylor, Katherine E Atkins, Gretchen B Chapman, and Alison P Galvani. 2016. "Stimulating influenza vaccination via prosocial motives." PLOS ONE, 11(7): e0159780.

Loewenstein, George F., Leigh Thompson, and Max H. Bazerman. 1989. "Social utility and decision making in interpersonal contexts." Journal of Personality and Social Psychology, $57(3): 426-441$.

Moffitt, Terrie E., Louise Arseneault, Daniel Belsky, Nigel Dickson, Robert J. Hancox, Hona Lee Harrington, Renate Houts, Richie Poulton, Brent W. Roberts, Stephen Ross, Malcolm R. Sears, W. Murray Thomson, and Avshalom Caspi. 2011. "A gradient of childhood self-control predicts health, wealth, and public safety." Proceedings of the National Academy of Sciences of the United States of America, 108(7): 2693-2698.

Molleman, Lucas, Felix Kölle, Chris Starmer, and Simon Gächter. 2019. "People prefer coordinated punishment in cooperative interactions." Nature Human Behaviour, 3(11): 11451153.

Müller, Stephan, and Holger A. Rau. 2020. "Economic preferences and compliance in the social stress test of the Corona crisis." Cege DP 391.

Oster, Emily. 2019. "Unobservable selection and coefficient stability: Theory and evidence." Journal of Business and Economic Statistics, 37(2): 187-204.

Peak, Corey M., Lauren M. Childs, Yonatan H. Grad, and Caroline O. Buckee. 2017. "Comparing nonpharmaceutical interventions for containing emerging epidemics." Proceedings of the National Academy of Sciences of the United States of America, 114(15): 4023-4028.

Prem, Kiesha, Yang Liu, Timothy W. Russell, Adam J. Kucharski, Rosalind M. Eggo, Nicholas Davies, Stefan Flasche, Samuel Clifford, Carl A.B. Pearson, James D. Munday, Sam Abbott, Hamish Gibbs, Alicia Rosello, Billy J. Quilty, Thibaut Jombart, Fiona Sun, Charlie Diamond, Amy Gimma, Kevin van Zandvoort, Sebastian Funk, Christopher I. Jarvis, W. John Edmunds, Nikos I. Bosse, Joel Hellewell, Mark Jit, and Petra Klepac. 2020. "The effect of control strategies to reduce social mixing on outcomes of the COVID19 epidemic in Wuhan, China: a modelling study." The Lancet Public Health.

Rand, David G., Anna Dreber, Tore Ellingsen, Drew Fudenberg, and Martin A. Nowak. 2009. "Positive interactions promote public cooperation." Science, 325(5945): 1272-1275.

Rosenthal, Robert. 1966. Experimenter effects in behavioral research. Appleton-CenturyCrofts. 
Rustichini, Aldo, Colin G. DeYoung, Jon C. Anderson, and Stephen V. Burks. 2012. "Toward the integration of personality theory and decision theory in the explanation of economic and health Behavior." IZA DP No. 6750.

Schilbach, Frank. 2019. "Alcohol and self-control: A field experiment in India." American Economic Review, 109(4): 1290-1322.

Strickhouser, Jason E., Ethan Zell, and Zlatan Krizan. 2017. "Does personality predict health and well-being? A metasynthesis." Health Psychology, 36(8): 797-810.

Stutzer, Alois, and Armando N. Meier. 2016. "Limited Self-control, Obesity, and the Loss of Happiness." Health Economics, 25(11): 1409-1424.

Sutter, Matthias, Martin G. Kocher, Glätzle Rützler Daniela, and Stefan T. Trautmann. 2013. "Impatience and uncertainty: Experimental decisions predict adolescents' field behavior." American Economic Review, 103(1): 510-531.

Taub Amanda. 2020. "How domestic abuse has risen worldwide since coronavirus." The New York Times.

Thunström, Linda, Madison Ashworth, Jason F. Shogren, Stephen Newbold, and David Finnoff. 2020. "Testing for COVID-19: Willful ignorance or selfless behavior?" Behavioral Public Policy, forthcoming.

Tricomi, Elizabeth, Antonio Rangel, Colin F. Camerer, and John P. Odoherty. 2010. "Neural evidence for inequality-averse social preferences." Nature, 463(7284): 1089-1091.

Turiano, Nicholas A., Patrick L. Hill, Eileen K. Graham, and Daniel K. Mroczek. 2018. "Associations between personality and health behaviors across the life span." In The Oxford Handbook of Integrative Health Science. Ed.: Carol D. Ryff and Robert F. Krueger.

Vieider, Ferdinand M., Mathieu Lefebvre, Ranoua Bouchouicha, Thorsten Chmura, Rustamdjan Hakimov, Michal Krawczyk, and Peter Martinsson. 2015. "Common components of risk and uncertainty attitudes across contexts and domains: Evidence from 30 countries." Journal of the European Economic Association, 13(3): 421-452.

Vollrath, Margarete, and Svenn Torgersen. 2002. "Who takes health risks? A probe into eight personality types." Personality and Individual Differences, 32(7): 1185-1197.

WGI. 2018. "CAF world giving index 2018."

Zettler, Ingo, Christoph Schild, Lau Lilleholt, and Robert Böhm. 2020. "Individual differences in accepting personal restrictions to fight the COVID-19 pandemic: Results from a Danish adult sample." PsyArXiv preprint.

Zizzo, Daniel John. 2010. "Experimenter demand effects in economic experiments." Experimental Economics, 13(1): 75-98. 


\title{
Prosociality predicts health behaviors during the COVID-19 pandemic
}

\author{
Pol Campos-Mercade ${ }^{\star} \quad$ Armando N. Meier ${ }^{\dagger}$ \\ Florian H. Schneider ${ }^{\ddagger}$ Erik Wengström ${ }^{\times}$
}

\section{Appendix}

\section{Table of Contents}

A Design of the surveys and distribution of responses 1

A.1 Measurement of social preferences: the Risk Dictator Game . . . . . . . . 1

A.2 Distribution of health behaviors in response to COVID-19 . . . . . . 4

A.3 Construction and distribution of indices of health behaviors . . . . . . 8

A.4 Validation of indices . . . . . . . . . . . . . . . . 10

B Additional results and robustness $\quad 11$

B.1 Graphical representation of the main results (scatterplots) . . . . . . . 11

B.2 Additional measures of prosociality . . . . . . . . . . . . . . . 12

B.3 Sensitivity and bounds of effect sizes given potential selection on unobservables . . . . . . . . . . . . . . . . . . . . . 14

B.4 Single behavioral items . . . . . . . . . . . . . . . . . . 16

$\begin{array}{lll}\text { C } & \text { Sample statistics and participation } & 17\end{array}$

$\begin{array}{lll}\text { D Instructions } & 19\end{array}$

D.1 Questions on health behaviors . . . . . . . . . . . . . . . . . 19

D.2 Social preferences and risk preferences . . . . . . . . . . . . 22

D.3 Personality measures, time preferences, health and worries . . . . . . . 26

${ }^{\star}$ Pol Campos-Mercade, University of Copenhagen (pcm@econ.ku.dk)

${ }^{\dagger}$ Armando N. Meier, University of Chicago Booth School of Business (armando.meier@chicagobooth.edu)

${ }^{\ddagger}$ Florian H. Schneider, University of Zurich (florian.schneider2@uzh.ch)

${ }^{\times}$Erik Wengström, Lund University (erik.wengstrom@nek.lu.se) 


\section{A Design of the surveys and distribution of responses}

\section{A.1 Measurement of social preferences: the Risk Dictator Game}

Figure A.1: Distribution of choices capturing prosociality
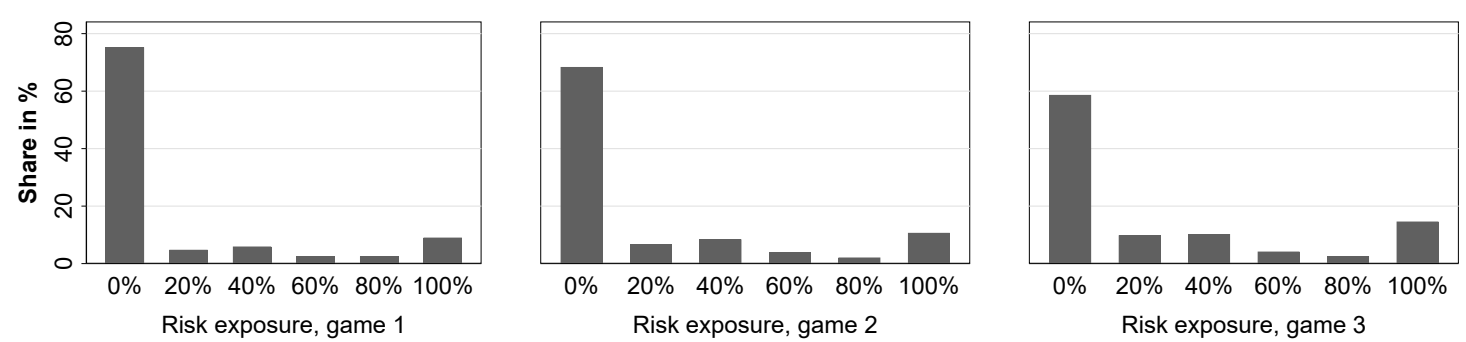

(a) Small

benefit(b)

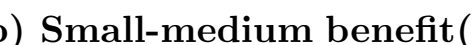

c) Medium

benefit $(\mathrm{X}=\$ 0.5)$ $(\mathrm{X}=\$ 1)$ $(\mathrm{X}=\$ 2)$
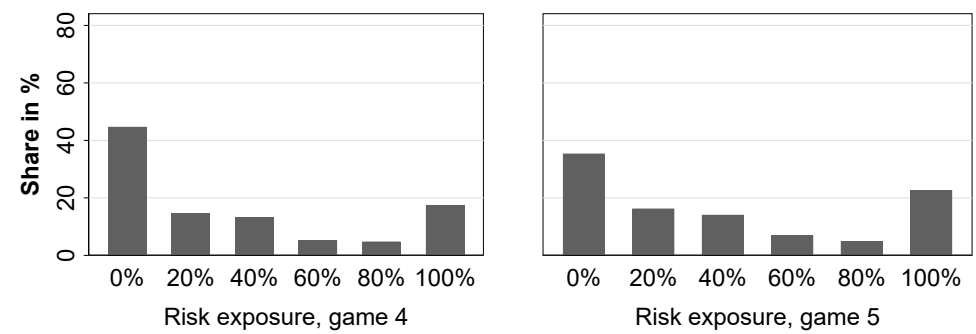

(d) Medium-large benefit(e) $(\mathrm{X}=\$ 5)$

benefit $(\mathrm{X}=\$ 10)$

Note: The figure shows the distribution of choices in the five Risk Dictator Games. The title of the panels capture the extent to which it is beneficial for the dictator to expose the recipient to risk. 
Figure A.2: Distribution of prosociality: willingness to expose others to risk

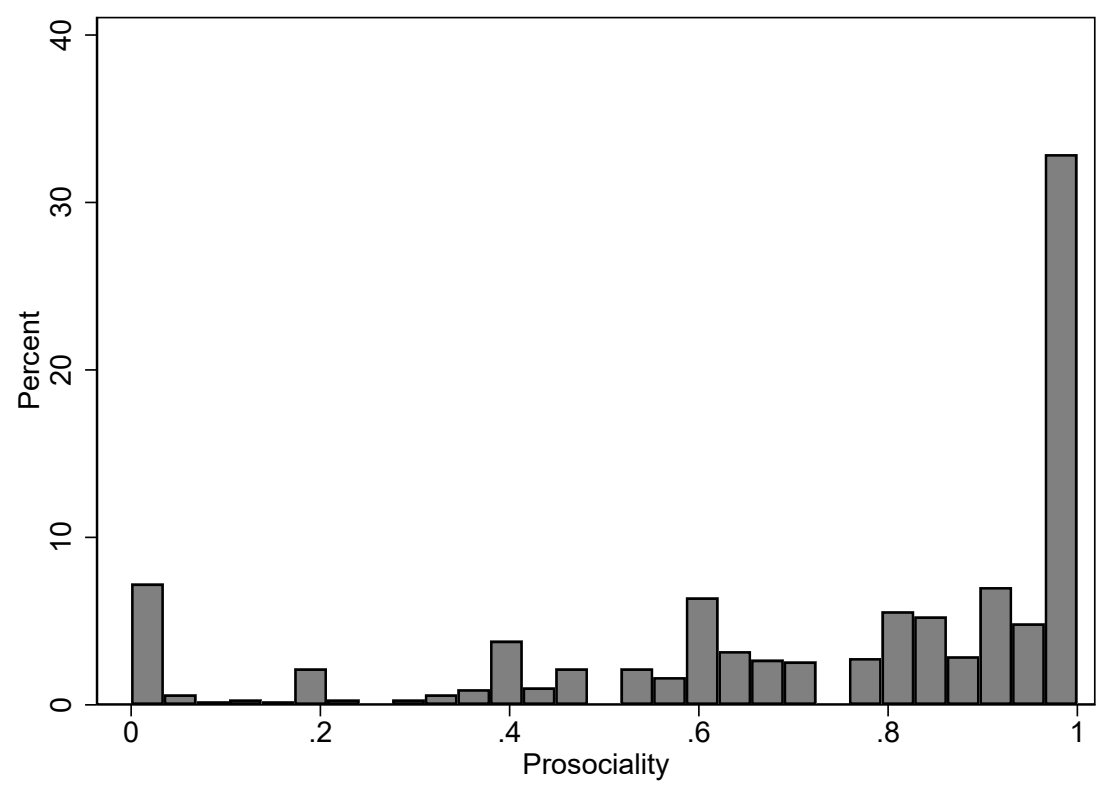

Note: The figure shows the distribution of our measure of prosociality. We construct this measure based on the five choices in the Risk Dictator Game. Let $r\left(c_{i, g}\right) \in\{0,0.2,0.4,0.6,0.8,1\}$ be the risk participant $i$ puts on the other player in game $g \in\{1, \ldots, 5\}$. We measure $i$ 's prosociality as $1-1 / 5 \sum_{g=1}^{5} r\left(c_{i, g}\right)$, that is, one minus the average risk she puts on the other player. The measure has a value of 1 if the participant always choose the option that puts no risk on the other player, and 0 if the participant always choose the option that puts the maximal risk on the other player. 
Figure A.3: Correlation of prosociality measures
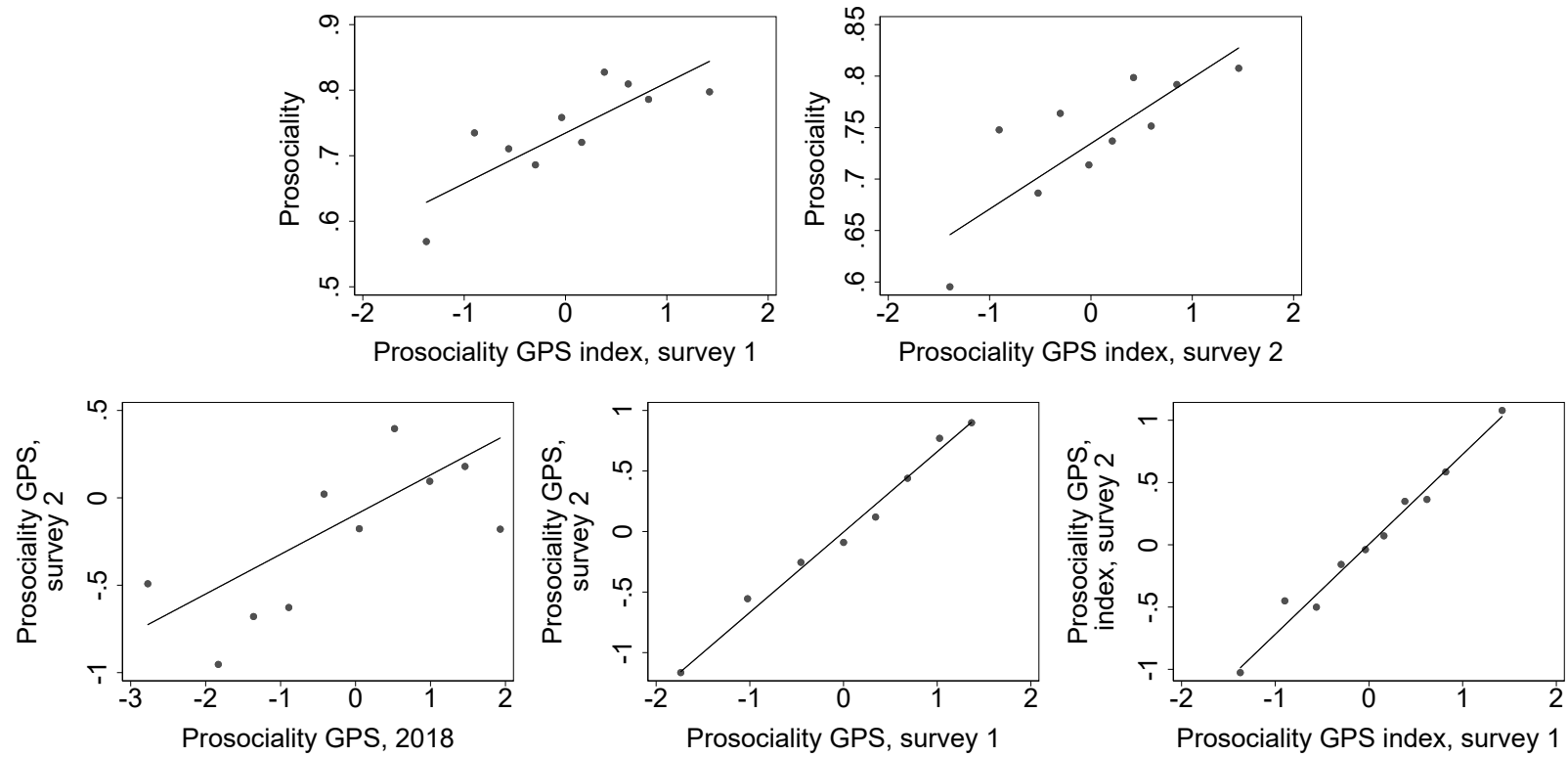

Note: The figures show the correlations between different measures of prosociality. "Prosociality" is our main measure. Moreover, we measure "Prosociality GPS" in both the health behavior survey (survey 1) and the social preferences survey (survey 2). We call these measures Prosociality GPS, survey 1 and Prosociality GPS, survey 2. We also have the same measure for 2018 study Prosociality GPS, 2018. Finally, "Prosociality GPS index" is an index based on Prosociality GPS and Prosociality GPS, item 2 which we collected in the health behavior survey and the social preferences survey. 
Figure A.4: Distribution of health behaviors that form the basis of the health behavior indices 1,2 , and 4
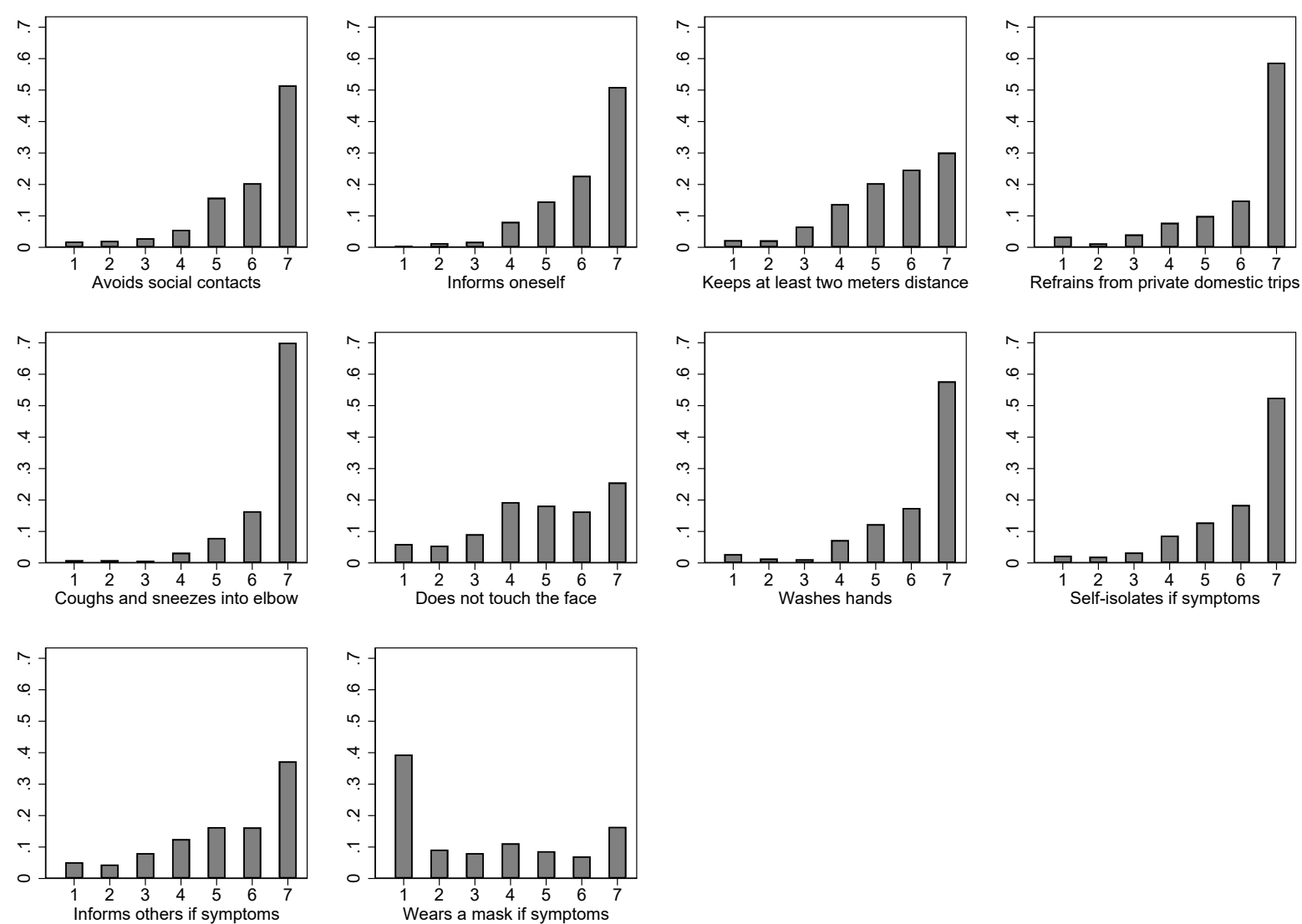

Note: For each item, we ask participants to what degree the described behavior applies to their own behavior on a 7-point scale from "does not apply at all" to "applies very much." 
Figure A.5: Distribution of health behaviors that form the basis of the health behavior index 3
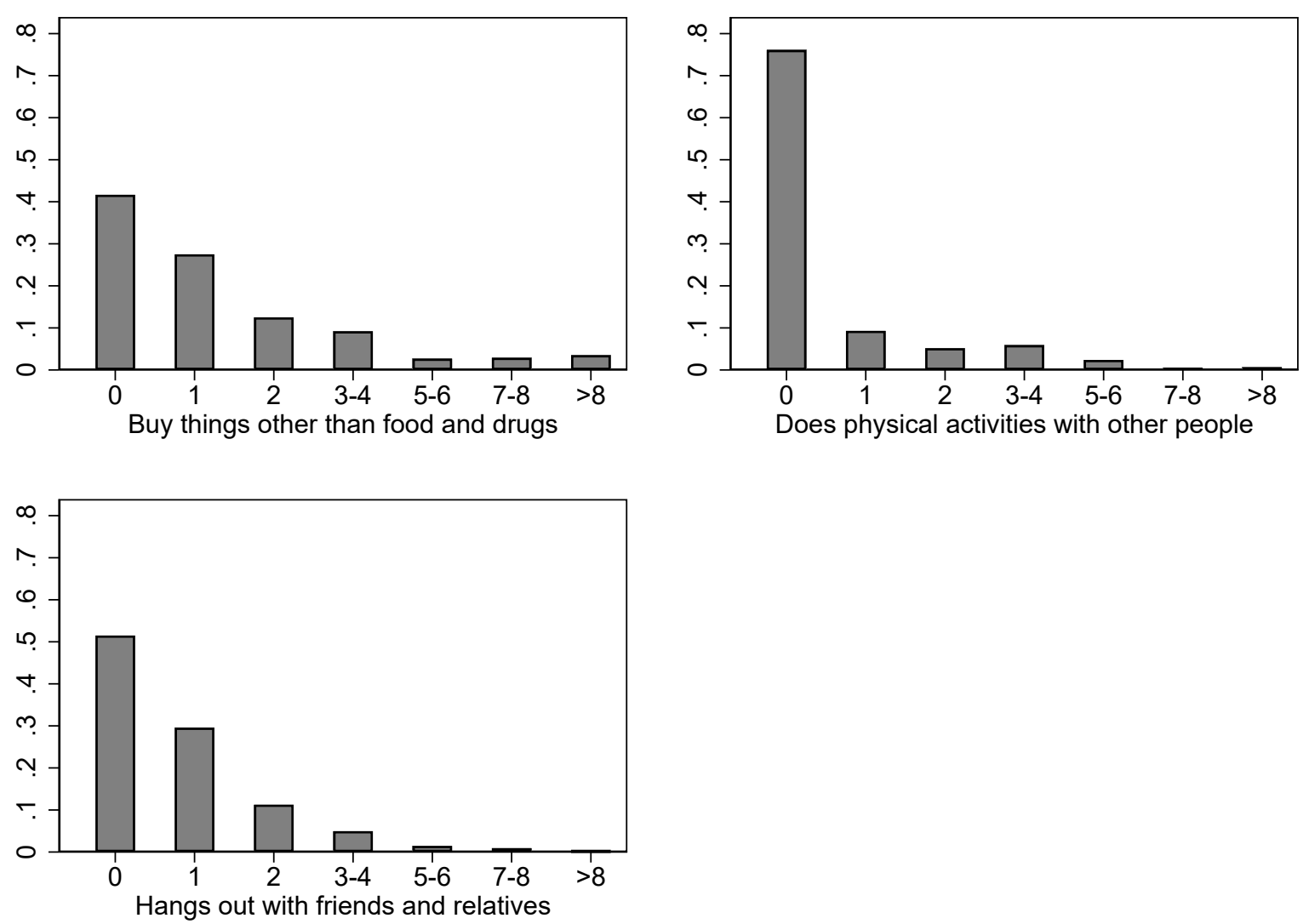

Note: We asked participants how often they left their home in the last 7 days for each of these three reasons. Possible answers were: Never, 1, 2, 3-4, 5-6, 7-8 or more than 8 times. 
Figure A.6: Distribution of clicks which form the basis for "information seeking"
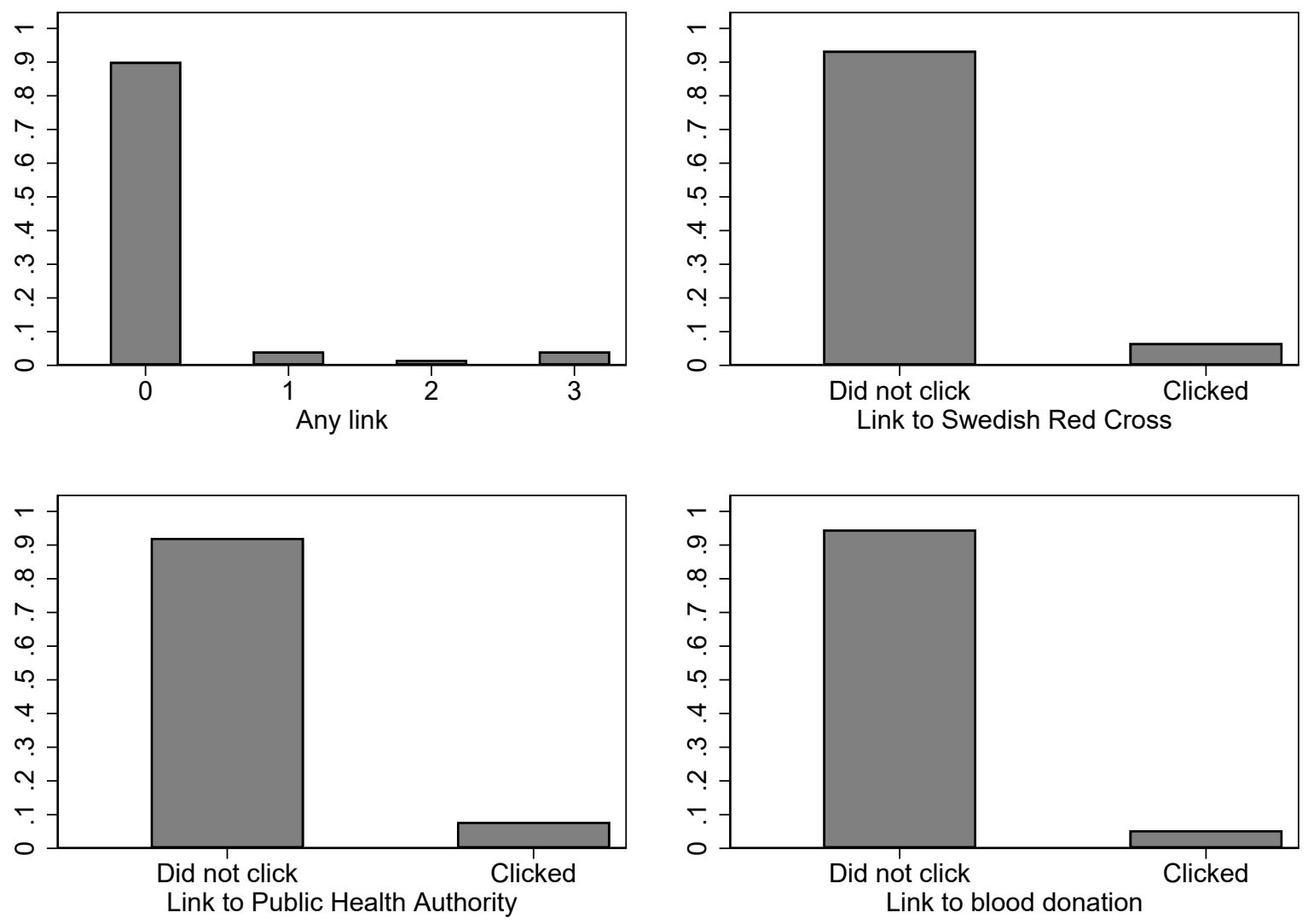

Note: We measured whether participants clicked different links to information about how to fight the COVID-19 pandemic. On the webpage of the Swedish Red Cross, participants learn more about how to help the weakest and healthcare professionals. On the webpage of the Public Health Authority, participants learn about the latest updates on how to help and protect others. On the webpage on blood donations, participants learn how they can donate blood, as there is a lack of blood in Sweden related to COVID-19. 
Figure A.7: Distribution of donation amounts to the COVID-19 fund - "donation to COVID-19 fund"

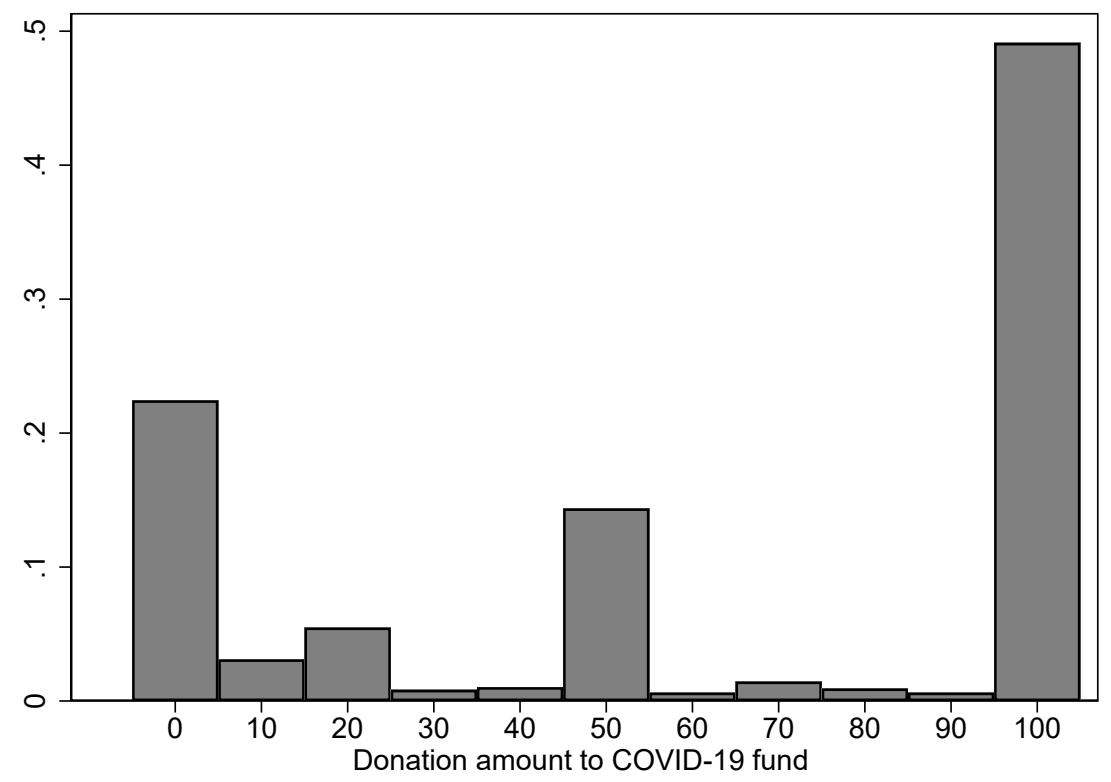

Note: Distribution of participants' donation (in between SEK 0 and SEK 100) to a solidarity response fund by the World Health Organization and UNICEF to fight the COVID-19 pandemic.

Figure A.8: Distribution of choice between money and a cloth face mask - "buys a cloth face mask"

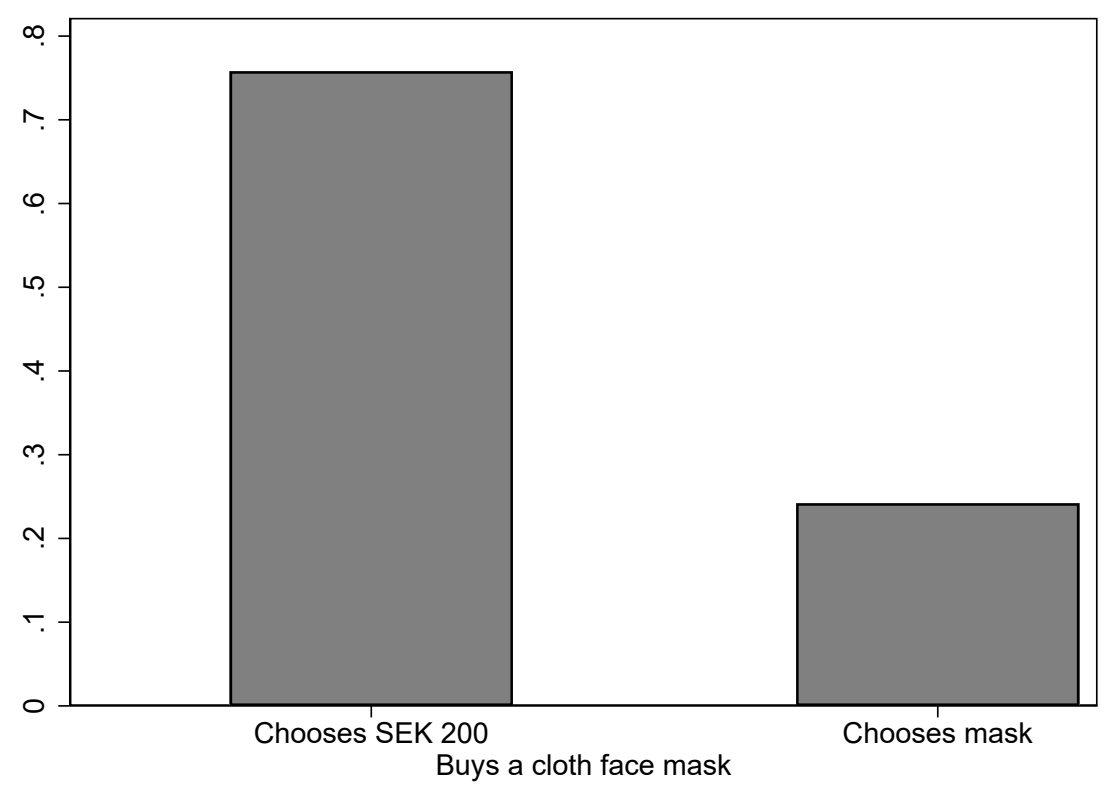

Note: We asked participants to chose between a cloth face mask and SEK 200. The figure shows the distribution of choices. 


\section{A.3 Construction and distribution of indices of health behaviors}

To elicit the perception of how effective different behaviors are in reducing the infection risk of others, we implemented a short survey with an independent sample of 100 Swedes, recruited on Prolific Academic. We ask participants:

"How much do the following behaviors protect yourself and protect others from getting infected by the coronavirus (COVID-19)? Please indicate your answer on a scale from 0 to 10, where 0 means "not protective at all" and 10 means "very protective".

For each behavior in Table C.1 we ask them how much it "protects me" and, separately, how much it "protects others." 10

The items in Health behaviors index 1 are perceived as being very effective in protecting others and moderately effective in protecting oneself. The items in Health behaviors index 2 and Health behaviors index 3 are perceived as being very effective in protecting others and oneself. The items in Health behaviors index 4 are perceived as being moderately effective in protecting others and very effective in protecting oneself.

\footnotetext{
${ }^{10}$ We did not ask about "refrain from private domestic trips." We added this item later as there was a lively discussion in Sweden about domestic trips few days after we ran the survey on Prolific Academic. We elicited the perception of this measure in a follow-up survey with 91 Swedes five days after the first survey. Both surveys were implemented before we collected the data. We preregistered the classification of all items in these four indices in our pre-analysis plan.
} 
Table A.1: Perception of health behaviors

\begin{tabular}{|c|c|c|}
\hline & $\begin{array}{l}\text { Mean rating } \\
\text { protects me }\end{array}$ & $\begin{array}{l}\text { Mean rating } \\
\text { protects others }\end{array}$ \\
\hline \multicolumn{3}{|l|}{ Health behaviors index 1} \\
\hline self-isolate if symptoms & $\begin{array}{c}4.76 \\
(4.08)\end{array}$ & $\begin{array}{c}8.97 \\
(1.53)\end{array}$ \\
\hline cough and sneeze into elbow & $\begin{array}{c}4.24 \\
(3.73)\end{array}$ & $\begin{array}{c}7.66 \\
(2.02)\end{array}$ \\
\hline inform others if symptoms & $\begin{array}{c}3.95 \\
(3.77)\end{array}$ & $\begin{array}{c}7.24 \\
(2.76)\end{array}$ \\
\hline wearing a mask if symptoms & $\begin{array}{l}4.27 \\
(3.3)\end{array}$ & $\begin{array}{c}7.01 \\
(2.65)\end{array}$ \\
\hline \multicolumn{3}{|l|}{ Health behaviors index 2} \\
\hline avoid social contacts & $\begin{array}{c}8.32 \\
(1.73)\end{array}$ & $\begin{array}{c}8.29 \\
(1.83)\end{array}$ \\
\hline inform how spread can be prevented & $\begin{array}{c}7.71 \\
(2.24)\end{array}$ & $\begin{array}{c}7.79 \\
(2.23)\end{array}$ \\
\hline keep at least two meters distance & $\begin{array}{l}7.53 \\
(2.2)\end{array}$ & $\begin{array}{c}7.75 \\
(1.91)\end{array}$ \\
\hline refrain from private domestic trips & $\begin{array}{c}7.2 \\
(2.58)\end{array}$ & $\begin{array}{c}7.42 \\
(2.56)\end{array}$ \\
\hline \multicolumn{3}{|l|}{ Health behaviors index 3} \\
\hline leave the house to buy non-essentials & $\begin{array}{c}7.31 \\
(2.41)\end{array}$ & $\begin{array}{c}7.45 \\
(2.43)\end{array}$ \\
\hline go out for physical activities with others & $\begin{array}{c}7.14 \\
(2.77)\end{array}$ & $\begin{array}{c}7.26 \\
(2.79)\end{array}$ \\
\hline hang out in person with others & $\begin{array}{c}7.02 \\
(2.43)\end{array}$ & $\begin{array}{c}7.16 \\
(2.41)\end{array}$ \\
\hline \multicolumn{3}{|l|}{ Health behaviors index 4} \\
\hline not touch the face & $\begin{array}{c}6.88 \\
(2.33)\end{array}$ & $\begin{array}{c}4.84 \\
(2.89)\end{array}$ \\
\hline wash hands & $\begin{array}{c}8.08 \\
(1.93) \\
\end{array}$ & $\begin{array}{c}7.08 \\
(2.62) \\
\end{array}$ \\
\hline
\end{tabular}




\section{A.4 Validation of indices}

Table A.2: Self-reported behaviors predict incentivized measures of health behaviors

\begin{tabular}{|c|c|c|c|}
\hline \multirow[t]{3}{*}{ Independent variable: } & \multicolumn{3}{|c|}{ Dependent variable: } \\
\hline & $\begin{array}{l}\text { Buys cloth } \\
\text { face mask }\end{array}$ & $\begin{array}{l}\text { Information } \\
\text { seeking }\end{array}$ & $\begin{array}{l}\text { Donation to } \\
\text { COVID-19 fund }\end{array}$ \\
\hline & (1) & $(2)$ & $(3)$ \\
\hline Health behaviors index 1 & $\begin{array}{l}0.14^{* * *} \\
(0.03)\end{array}$ & $\begin{array}{l}0.06^{* *} \\
(0.03)\end{array}$ & $\begin{array}{l}0.16^{* * * *} \\
(0.03)\end{array}$ \\
\hline Health behaviors index 2 & $\begin{array}{l}0.11^{* * *} \\
(0.03)\end{array}$ & $\begin{array}{c}0.03 \\
(0.03)\end{array}$ & $\begin{array}{l}0.19^{* * *} \\
(0.04)\end{array}$ \\
\hline Health behaviors index 3 & $\begin{array}{c}0.05 \\
(0.05)\end{array}$ & $\begin{array}{c}0.06^{*} \\
(0.04)\end{array}$ & $\begin{array}{l}0.16^{* * * *} \\
(0.05)\end{array}$ \\
\hline Health behaviors index 4 & $\begin{array}{l}0.06^{* *} \\
(0.03)\end{array}$ & $\begin{array}{c}0.03 \\
(0.03)\end{array}$ & $\begin{array}{l}0.15^{* * * *} \\
(0.03)\end{array}$ \\
\hline \multicolumn{4}{|l|}{ Controls: } \\
\hline Age and gender & yes & yes & yes \\
\hline Individuals & 967 & 967 & 967 \\
\hline
\end{tabular}

Note: The self-reported behaviors are consistent with the measures of actual behavior. The table shows the relationship between the four self-reported indices of behaviors during the COVID-19 pandemic and our three incentivized behaviors in the survey (buys cloth face mask, information seeking and donation to the COVID-19 fund). The table gives the coefficients from linear regressions (dependent variables are the incentivized measures), controlling for age and gender. Heteroscedasticity robust standard errors are shown in parentheses. $\mathrm{P}$-values are based on one-sided tests. ${ }^{*} p<0.10,{ }^{* *} p<0.05,{ }^{* * *} p<0.01$ 


\section{B Additional results and robustness}

\section{B.1 Graphical representation of the main results (scatterplots)}

Figure B.1: Relationships between behaviors and prosociality
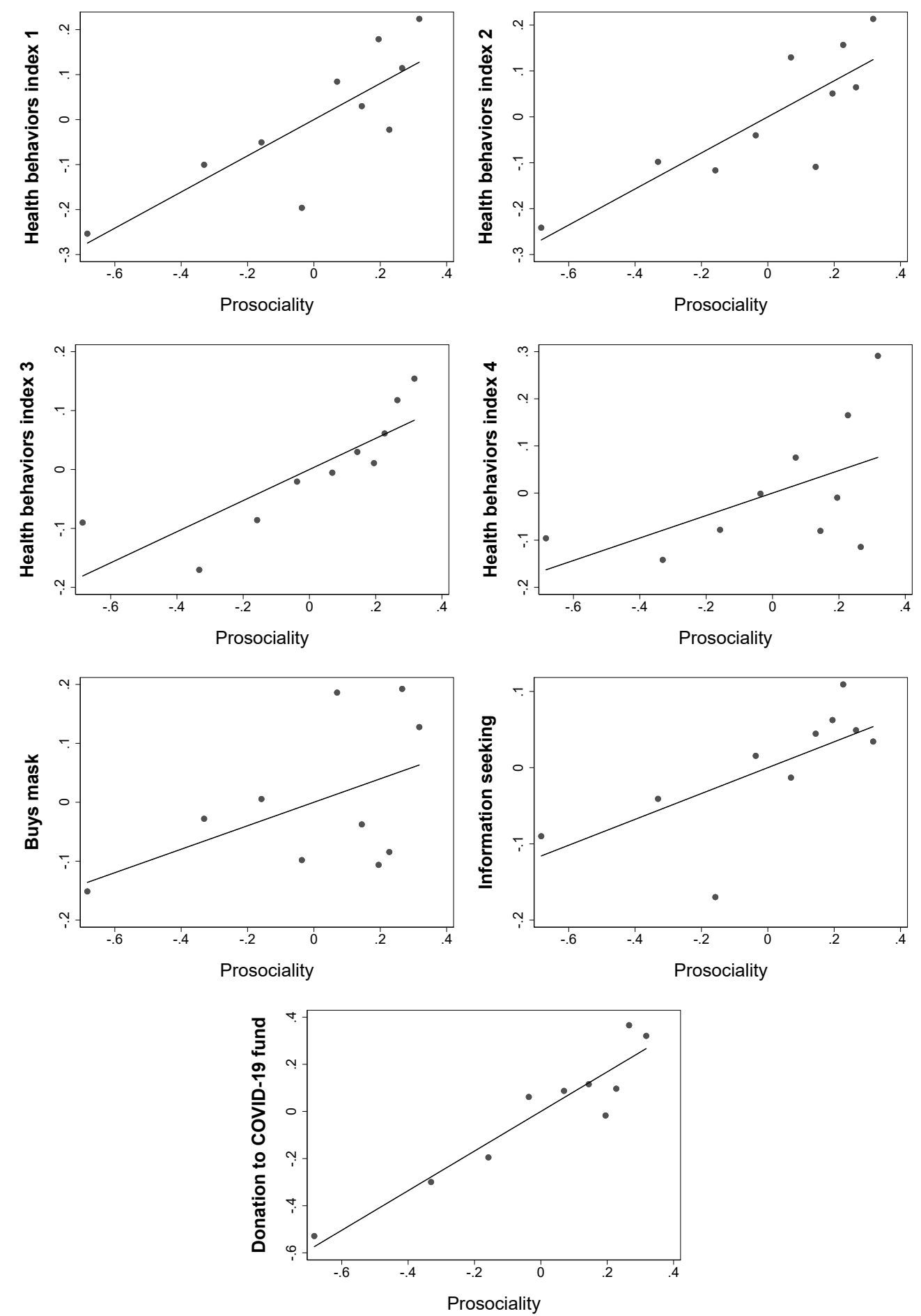

Note: The figure shows the relationship between outcomes and prosociality conditional on age and gender across deciles of prosociality. It also controls for past behavior when looking at health behaviors index 3 . 


\section{B.2 Additional measures of prosociality}

Figure B.2: Prosociality GPS indices in the 2020 surveys predict health behaviors

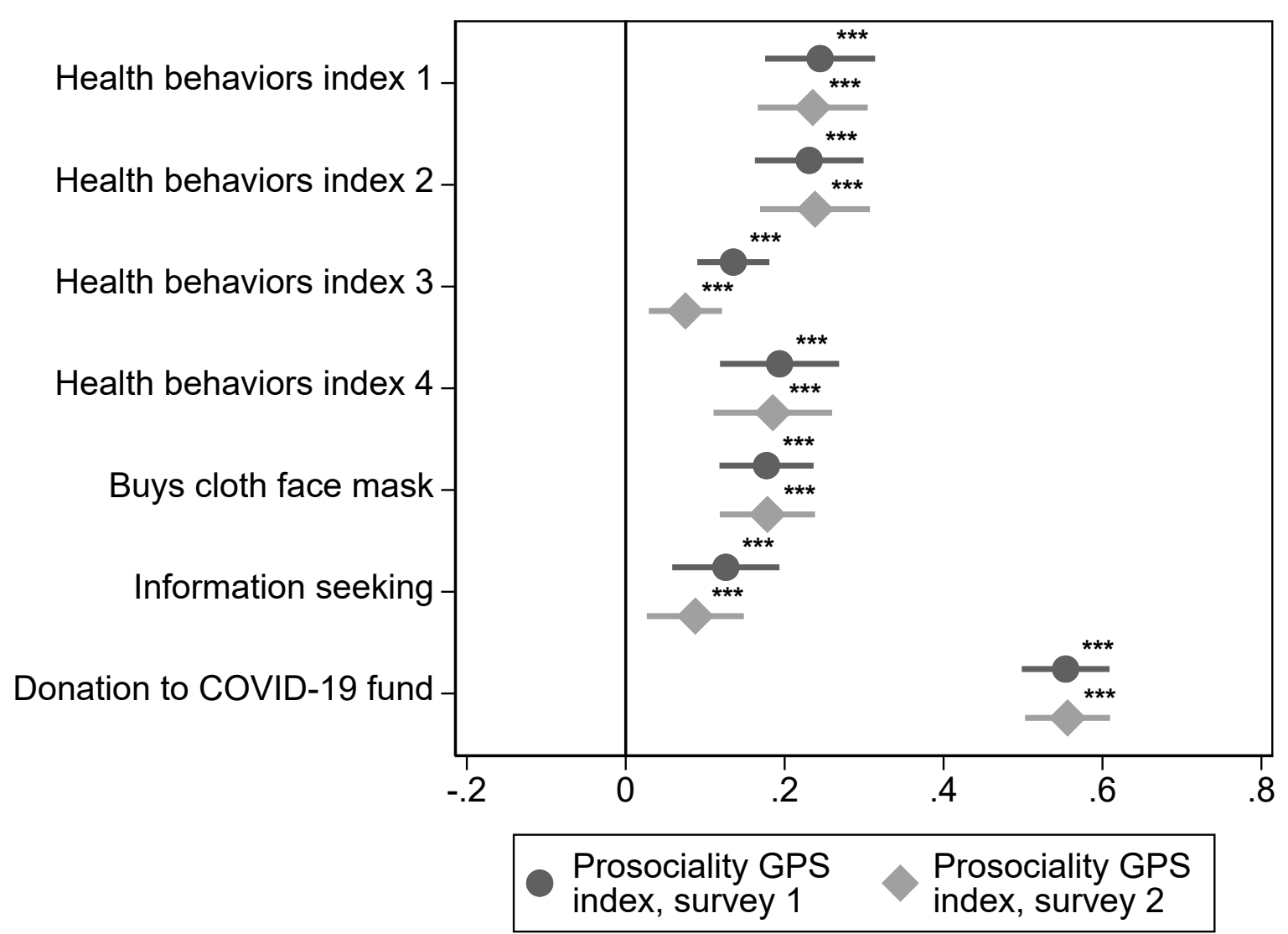

Note: The figure shows coefficient estimates from a linear regression of the outcome variable (shown on the left) on two alternative measures of prosociality collected in 2020, controlling for age and gender (preregistered specification). The figure replicates Figure 2 using indices of prosociality. Prosociality is captured by an index from two experimentally validated questions on people's willingness to give to a good cause without expecting anything in return and giving to charity used in the Global Preference Survey. We collected this measure both in the health behavior survey (survey 1) and the social preferences survey (survey 2). 
Table B.1: Prosociality GPS index in the social preferences survey predicts health behaviors controlling for other preferences, worries, health, and personality

\begin{tabular}{|c|c|c|c|c|c|c|c|c|}
\hline Dependent variable: & (1) & $(2)$ & $(3)$ & $\begin{array}{l}\text { Specific } \\
(4)\end{array}$ & $\begin{array}{r}\text { ration: } \\
(5)\end{array}$ & (6) & $(7)$ & $(8)$ \\
\hline Health behaviors index 1 & $\begin{array}{l}0.22^{* * *} \\
(0.04)\end{array}$ & $\begin{array}{l}0.20^{* * *} \\
(0.04)\end{array}$ & $\begin{array}{l}0.18^{* * *} \\
(0.04)\end{array}$ & $\begin{array}{l}0.22^{* * *} \\
(0.04)\end{array}$ & $\begin{array}{l}0.17^{* * *} \\
(0.04)\end{array}$ & $\begin{array}{l}0.16^{* * *} \\
(0.04)\end{array}$ & $\begin{array}{l}0.16^{* * *} \\
(0.04)\end{array}$ & $\begin{array}{l}0.16^{* * *} \\
(0.04)\end{array}$ \\
\hline Health behaviors index 2 & $\begin{array}{l}0.22^{* * *} \\
(0.04)\end{array}$ & $\begin{array}{l}0.19^{* * *} \\
(0.04)\end{array}$ & $\begin{array}{l}0.16^{* * * *} \\
(0.04)\end{array}$ & $\begin{array}{l}0.22^{* * *} \\
(0.04)\end{array}$ & $\begin{array}{l}0.16^{* * *} \\
(0.04)\end{array}$ & $\begin{array}{l}0.15^{* * *} \\
(0.04)\end{array}$ & $\begin{array}{l}0.15^{* * *} \\
(0.04)\end{array}$ & $\begin{array}{l}0.15^{* * *} \\
(0.04)\end{array}$ \\
\hline Health behaviors index 3 & $\begin{array}{l}0.07^{* * *} \\
(0.03)\end{array}$ & $\begin{array}{c}0.05^{*} \\
(0.03)\end{array}$ & $\begin{array}{c}0.05^{* *} \\
(0.03)\end{array}$ & $\begin{array}{l}0.07^{* * *} \\
(0.03)\end{array}$ & $\begin{array}{c}0.03 \\
(0.03)\end{array}$ & $\begin{array}{c}0.04 \\
(0.03)\end{array}$ & $\begin{array}{c}0.04 \\
(0.03)\end{array}$ & $\begin{array}{c}0.04 \\
(0.03)\end{array}$ \\
\hline Health behaviors index 4 & $\begin{array}{l}0.18^{* * *} \\
(0.05)\end{array}$ & $\begin{array}{l}0.16^{* * *} \\
(0.05)\end{array}$ & $\begin{array}{l}0.13^{* * *} \\
(0.04)\end{array}$ & $\begin{array}{l}0.18^{* * *} \\
(0.05)\end{array}$ & $\begin{array}{l}0.12^{* * *} \\
(0.04)\end{array}$ & $\begin{array}{l}0.11^{* * *} \\
(0.04)\end{array}$ & $\begin{array}{c}0.10^{* *} \\
(0.04)\end{array}$ & $\begin{array}{c}0.10^{* *} \\
(0.04)\end{array}$ \\
\hline Buys cloth face mask & $\begin{array}{l}0.18^{* * *} \\
(0.04)\end{array}$ & $\begin{array}{l}0.19^{* * *} \\
(0.04)\end{array}$ & $\begin{array}{l}0.15^{* * *} \\
(0.04)\end{array}$ & $\begin{array}{l}0.18^{* * *} \\
(0.04)\end{array}$ & $\begin{array}{l}0.17^{* * *} \\
(0.04)\end{array}$ & $\begin{array}{l}0.17^{* * *} \\
(0.04)\end{array}$ & $\begin{array}{l}0.16^{* * *} \\
(0.04)\end{array}$ & $\begin{array}{l}0.16^{* * *} \\
(0.04)\end{array}$ \\
\hline Information seeking & $\begin{array}{c}0.09^{* *} \\
(0.04)\end{array}$ & $\begin{array}{c}0.04 \\
(0.04)\end{array}$ & $\begin{array}{c}0.09^{* *} \\
(0.04)\end{array}$ & $\begin{array}{c}0.09^{* *} \\
(0.04)\end{array}$ & $\begin{array}{c}0.04 \\
(0.04)\end{array}$ & $\begin{array}{l}0.05 \\
(0.05)\end{array}$ & $\begin{array}{c}0.03 \\
(0.04)\end{array}$ & $\begin{array}{c}0.04 \\
(0.05)\end{array}$ \\
\hline Donation to COVID-19 fund & $\begin{array}{l}0.53^{* * * *} \\
(0.03)\end{array}$ & $\begin{array}{l}0.51^{* * * *} \\
(0.04)\end{array}$ & $\begin{array}{l}0.53^{* * * *} \\
(0.03)\end{array}$ & $\begin{array}{c}0.53^{* * *} \\
(0.03)\end{array}$ & $\begin{array}{l}0.50^{* * * *} \\
(0.04)\end{array}$ & $\begin{array}{l}0.50^{* * * *} \\
(0.04)\end{array}$ & $\begin{array}{l}0.48^{* * * *} \\
(0.04)\end{array}$ & $\begin{array}{l}0.48^{* * *} \\
(0.04)\end{array}$ \\
\hline \multicolumn{9}{|l|}{ Controls: } \\
\hline $\begin{array}{l}\text { Age and gender } \\
\text { Sociodemographics } \\
\text { Date and county }\end{array}$ & $\begin{array}{l}\text { yes } \\
\text { yes } \\
\text { yes }\end{array}$ & $\begin{array}{l}\text { yes } \\
\text { yes } \\
\text { yes }\end{array}$ & $\begin{array}{l}\text { yes } \\
\text { yes } \\
\text { yes }\end{array}$ & $\begin{array}{l}\text { yes } \\
\text { yes } \\
\text { yes }\end{array}$ & $\begin{array}{l}\text { yes } \\
\text { yes } \\
\text { yes }\end{array}$ & $\begin{array}{l}\text { yes } \\
\text { yes } \\
\text { yes }\end{array}$ & $\begin{array}{l}\text { yes } \\
\text { yes } \\
\text { yes }\end{array}$ & $\begin{array}{l}\text { yes } \\
\text { yes } \\
\text { yes }\end{array}$ \\
\hline $\begin{array}{l}\text { Risk and time preferences } \\
\text { Beliefs and worries } \\
\text { Health } \\
\text { Big } 5 \\
\text { Trust }\end{array}$ & & yes & yes & yes & $\begin{array}{l}\text { yes } \\
\text { yes } \\
\text { yes }\end{array}$ & $\begin{array}{l}\text { yes } \\
\text { yes } \\
\text { yes } \\
\text { yes }\end{array}$ & $\begin{array}{l}\text { yes } \\
\text { yes } \\
\text { yes }\end{array}$ & $\begin{array}{l}\text { yes } \\
\text { yes } \\
\text { yes } \\
\text { yes } \\
\text { yes }\end{array}$ \\
\hline Individuals & 967 & 967 & 967 & 967 & 967 & 967 & 967 & 967 \\
\hline
\end{tabular}

Note: The table shows coefficient estimates from linear regressions of the outcome variable (shown on the left) on prosociality. Prosociality is based on an index of prosociality measured in the social preferences survey. Heteroscedasticity robust standard errors are shown in parentheses. Sociodemographics include dummies for all education, number of children, household income, occupation, and marital status categories (see Appendix Table C.2 for all categories). Date and county refers to including categorical dummies for counties and response dates. In addition, regressions (3) and (5)-(8) also control for participants' risk aversion, beliefs about others' risk aversion, and patience. Regressions (4)-(8) control for participants' life expectancy (a proxy of their health) and whether participants worry about getting infected, that the healthcare will not be able to offer good care to everyone, that their finances will be hit hard, and that the Swedish economy will be hit hard. Regressions (6) and (8) control for the Big Five traits and regressions (7)-(8) for trust. As preregistered, $p$-values are based on one-sided tests. ${ }^{*} p<0.10,{ }^{* *} p<0.05,{ }^{* * *} p<0.01$ 
Table B.2: Different measures of prosociality predict health behaviors

\begin{tabular}{lccccc}
\hline Dependent variable: & Prosociality & $\begin{array}{c}\text { Independent variable: } \\
\text { Prosociality } \\
\text { GPS Index } \\
\text { Prosociality } \\
\text { GPS Index } \\
\text { Prosociality } \\
\text { GPS }\end{array}$ & $\begin{array}{c}\text { Prosociality } \\
\text { GPS } \\
\text { Survey } 2\end{array}$ & $\begin{array}{c}\text { Survey } 2 \\
\text { Survey 2018 }\end{array}$ \\
\cline { 2 - 6 } & $(1)$ & $(2)$ & $(3)$ & $(4)$ & $(5)$ \\
\hline Health behaviors index 1 & $0.40^{* * *}$ & $0.24^{* * *}$ & $0.24^{* * *}$ & $0.19^{* * *}$ & $0.15^{* *}$ \\
Health behaviors index 2 & $(0.12)$ & $(0.04)$ & $(0.04)$ & $(0.03)$ & $(0.08)$ \\
Health behaviors index 3 & $0.39^{* * *}$ & $0.23^{* * *}$ & $0.24^{* * *}$ & $0.20^{* * *}$ & $0.13^{*}$ \\
Health behaviors index 4 & $(0.12)$ & $(0.04)$ & $(0.04)$ & $(0.03)$ & $(0.08)$ \\
Buys cloth face mask & $0.26^{* * *}$ & $0.14^{* * *}$ & $0.08^{* * *}$ & $0.07^{* * *}$ & 0.02 \\
Information seeking & $(0.08)$ & $(0.03)$ & $(0.03)$ & $(0.02)$ & $(0.05)$ \\
Donation to COVID-19 fund & $0.24^{* *}$ & $0.19^{* * *}$ & $0.19^{* * *}$ & $0.15^{* * *}$ & $0.16^{* *}$ \\
& $(0.12)$ & $(0.05)$ & $(0.05)$ & $(0.04)$ & $(0.09)$ \\
& $0.20^{* *}$ & $0.18^{* * *}$ & $0.18^{* * *}$ & $0.11^{* * *}$ & 0.04 \\
Age and gender & $(0.10)$ & $(0.04)$ & $(0.04)$ & $(0.03)$ & $(0.07)$ \\
\hline \hline Individuals & $0.17^{*}$ & $0.13^{* * *}$ & $0.09^{* * *}$ & $0.09^{* * *}$ & $0.10^{* *}$ \\
\hline & $(0.10)$ & $(0.04)$ & $(0.04)$ & $(0.03)$ & $(0.05)$ \\
\hline
\end{tabular}

Note: The table shows coefficient estimates from linear regressions of the outcome variable (shown on the left) on different measures of prosociality controlling for age and gender (preregistered specification). Heteroscedasticity robust standard errors are shown in parentheses. As preregistered, $p$-values are based on one-sided tests. $* p<0.10,{ }^{* *} p<0.05,{ }^{* * *} p<0.01$

\section{B.3 Sensitivity and bounds of effect sizes given potential selection on unobservables}

Coefficient estimates can be bound using the reaction of the estimate to the inclusion of controls and fixed effects - if the controls are informative about unobservables (Oster, 2019). This seems reasonable in our setting because measures such as our version of the Big Five questionnaire are most likely correlated with unobservables that we would measure using different personality questionnaires. If the effect size does not vary much with the inclusion of controls compared to the increase in the variation explained, the $R^{2}$, it is unlikely that the bias caused by unobservables is large (Oster, 2019). We have to make an assumption on the attainable $R^{2}$ in our setting to apply the method. We follow the proposition by Oster to assume an attainable $R^{2}$ of 1.3 times the $R^{2}$ of the specification with all the controls. In 
our case, this corresponds to 1.3 times the $\mathrm{R}$-squared in specification (8) of Table 2 for the dependent variable health behaviors index $1 .^{11}$

Table B.3: Sensitivity of effect sizes to unobservables

\begin{tabular}{lcccc}
\hline Independent variable: & \multicolumn{3}{c}{ Specification includes: } \\
& \multicolumn{2}{c}{ Risk \& time prefs., } & \multicolumn{2}{c}{ All } \\
& worries \& health & \multicolumn{2}{c}{ controls } \\
& $\beta^{*}$ & $\delta$ & $\beta^{*}$ & $\delta$ \\
\hline Health behaviors index 1 & 0.23 & 2.92 & 0.21 & 2.81 \\
Health behaviors index 2 & 0.27 & 10.81 & 0.27 & 16.93 \\
Health behaviors index 3 & 0.16 & 12.07 & 0.17 & 16.79 \\
Health behaviors index 4 & 0.17 & 3.21 & 0.15 & 3.21 \\
Buys cloth face mask & 0.33 & -33.60 & 0.34 & -25.28 \\
Information seeking & -0.11 & 0.66 & -0.12 & 0.64 \\
Donation to COVID-19 fund & 0.75 & 3.72 & 0.74 & 4.27 \\
\hline \hline \multirow{2}{*}{ Individuals } & \multirow{2}{*}{967} & 967 & 967 & 967 \\
\hline
\end{tabular}

Note: The table shows lower bound estimates of the effect, $\beta^{*}$, and the selection parameter, $\delta$, which indicates how much more of the selection would have to be explained by unobservables rather than observables for the true effect to be zero. Standard errors specified for the estimation are heteroscedasticity robust. The estimates in the first two columns are based on a comparison of the $\mathrm{R}$-squared including risk and time preferences, worries, and health as in specification (6) of Table 2 to the $\mathrm{R}-$ squared including only age and gender as controls. The estimates in the third and fourth column are based on a comparison of the $\mathrm{R}$-squared including all controls as in specification (8) of Table 2 to the $\mathrm{R}$-squared including only age and gender as controls.

On the basis of this assumption we estimate two parameters: $\delta$ and $\beta^{*}$ Parameter $\delta$ indicates how much larger the selection on unobservables would have to be, compared to the selection on observables, for the true causal effect to be zero. Parameter $\beta^{*}$ gives the lower bound estimate of the causal effect assuming that the selection on unobservables is weakly smaller than the selection on observables $(\delta \leq 1)$.

In Table B. 3 we show $\beta^{*}$ and $\delta$ for comparing more rich specifications with the specification including only age and gender. Except for information seeking, the lower bound estimates are all much larger than 0 . The smallest $\delta$ of our key results is 2.8 , which means that the selection on unobservables would have to be more than 2.8 times larger than what we capture with

\footnotetext{
${ }^{11}$ Oster shows that more than $90 \%$ of the results from randomized controlled trials survive this threshold, while less than $60 \%$ of the results from observational data survive. Since the experimental results are likely causal estimates, Oster suggests using the experimental results as a benchmark and choosing the maximal attainable $R^{2}$ such that $90 \%$ of the experimental results survive. In our case the maximally attainable $\mathrm{R}$-squared is $0.25 * 1.3=0.325$.
} 
the observables for any of the causal effects to be zero. The $\delta$ for buying a cloth face mask is negative, since the coefficient increases when adding additional controls (this is also why the coefficient estimate bound is larger than the corresponding coefficient estimate). Given these results and since we include controls for other key determinants of health behaviors, selection on unobservables seems unlikely to explain the effect of prosociality on health behaviors.

\section{B.4 Single behavioral items}

Figure B.3: Results for all behaviors that we aggregate into indices separately

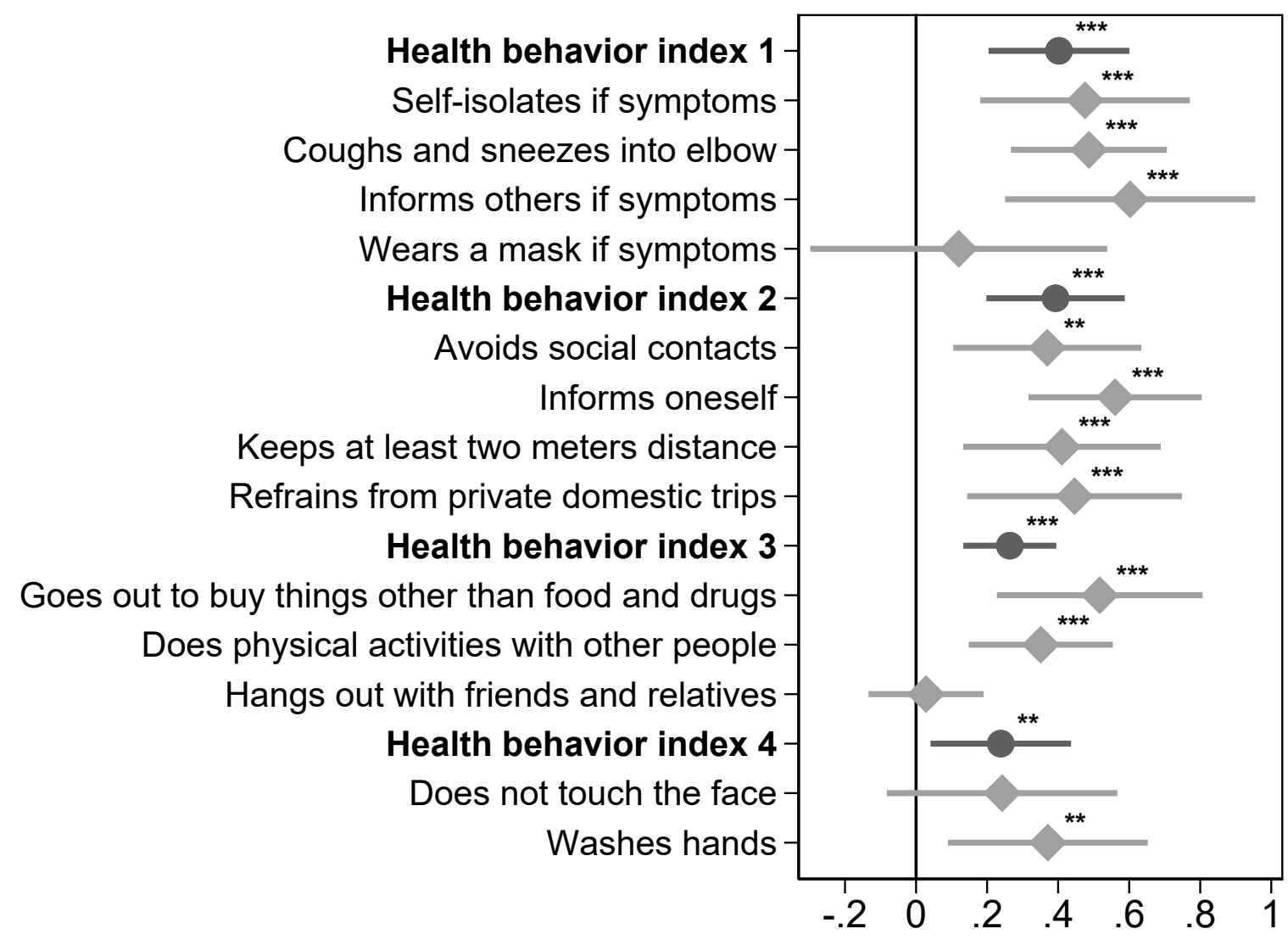

Note: The figure shows coefficient estimates from a linear regression of the outcome variable (shown on the left) on prosociality, controlling for age and gender (preregistered specification). The figure also shows standard errors bars corresponding to a two-sided significance test at the $10 \%$-level. The comparison against 0 corresponds to a one-sided significance test at the $5 \%$-level, as preregistered. ${ }^{*} p<0.10,{ }^{* *} p<0.05,{ }^{* * *} p<0.01$ 


\section{Sample statistics and participation}

Table C.1: Prosociality and retention after matching surveys

\begin{tabular}{lcccc}
\hline Dependent Variable & \multicolumn{4}{c}{ In sample: yes } \\
\cline { 2 - 5 } & $(1)$ & $(2)$ & $(3)$ & $(4)$ \\
\hline Prosociality GPS index & $\begin{array}{c}-0.01 \\
(0.02)\end{array}$ & $\begin{array}{c}-0.00 \\
(0.02)\end{array}$ & \\
Prosociality GPS & & & 0.00 & 0.01 \\
& & & $(0.01)$ & $(0.01)$ \\
Prosociality GPS, item 2 & & & -0.01 & -0.01 \\
& & & $(0.01)$ & $(0.01)$ \\
\hline Controls: & & & & \\
\hline Age and gender & \multicolumn{4}{c}{$\mathrm{X}$} \\
\hline \hline Individuals & 1,505 & 1,505 & 1,505 & 1,505 \\
$R$-squared & 0.00 & 0.02 & 0.00 & 0.02 \\
\hline$N$ - & & & \\
\hline
\end{tabular}

Note: This table shows the relationship between an indicator variable indicating being in our matched sample of the health behavior survey (first survey) and the social preferences survey (second survey) that we use for estimation and prosociality GPS measured in the health behavior survey (first survey). The table gives the coefficients from linear regressions, controlling for age and gender in specifications (2) and (4). Heteroscedasticity robust standard errors are shown in parentheses. Pvalues are based on one-sided tests.

$* p<0.10,{ }^{* *} p<0.05,{ }^{* * *} p<0.01$ 
Table C.2: Sample statistics

\begin{tabular}{|c|c|c|c|c|c|c|c|}
\hline \multirow[t]{2}{*}{ Variable } & \multicolumn{3}{|c|}{ Matched surveys 2020} & \multicolumn{3}{|c|}{ Survey 2018} & \multirow{2}{*}{$\begin{array}{c}\text { Sweden } \\
\text { Mean }\end{array}$} \\
\hline & $\mathrm{N}$ & Mean & $\mathrm{SD}$ & $\mathrm{N}$ & Mean & $\mathrm{SD}$ & \\
\hline Age & 967 & 46.70 & 15.80 & 197 & 47.55 & 11.44 & \\
\hline $18-25$ years & 967 & 0.10 & 0.29 & 197 & 0.03 & 0.17 & 0.12 \\
\hline 26-35 years & 967 & 0.20 & 0.40 & 197 & 0.13 & 0.34 & 0.18 \\
\hline $36-45$ years & 967 & 0.18 & 0.39 & 197 & 0.25 & 0.43 & 0.16 \\
\hline $46-55$ years & 967 & 0.22 & 0.41 & 197 & 0.30 & 0.46 & 0.17 \\
\hline $56-65$ years & 967 & 0.17 & 0.38 & 197 & 0.25 & 0.43 & 0.14 \\
\hline 66 years and older & 967 & 0.14 & 0.34 & 197 & 0.04 & 0.20 & 0.24 \\
\hline Female & 967 & 0.51 & 0.50 & 197 & 0.55 & 0.50 & 0.50 \\
\hline Region Stockholm & 967 & 0.33 & 0.47 & 197 & 0.32 & 0.47 & 0.23 \\
\hline Region Östra Mellansverige & 967 & 0.14 & 0.34 & 197 & 0.12 & 0.33 & 0.17 \\
\hline Region Småland med öarna & 967 & 0.06 & 0.24 & 197 & 0.07 & 0.25 & 0.08 \\
\hline Region Sydsverige & 967 & 0.14 & 0.35 & 197 & 0.11 & 0.32 & 0.15 \\
\hline Region Västsverige & 967 & 0.20 & 0.40 & 197 & 0.22 & 0.41 & 0.20 \\
\hline Region Norra Mellansverige & 967 & 0.06 & 0.24 & 197 & 0.07 & 0.26 & 0.08 \\
\hline Region Mellersta Norrland & 967 & 0.02 & 0.16 & 197 & 0.03 & 0.17 & 0.04 \\
\hline Region Övre Norrland & 967 & 0.05 & 0.21 & 197 & 0.05 & 0.22 & 0.05 \\
\hline Single & 967 & 0.38 & 0.48 & 197 & 0.45 & 0.50 & \\
\hline Living apart & 967 & 0.04 & 0.20 & 197 & 0.04 & 0.20 & \\
\hline Couple & 967 & 0.25 & 0.43 & 197 & 0.19 & 0.40 & \\
\hline Married & 967 & 0.31 & 0.46 & 197 & 0.31 & 0.46 & \\
\hline Other civil status & 967 & 0.02 & 0.14 & 197 & 0.01 & 0.07 & \\
\hline Elementary school & 967 & 0.07 & 0.25 & 197 & 0.06 & 0.24 & \\
\hline High-school & 967 & 0.34 & 0.47 & 197 & 0.37 & 0.48 & \\
\hline Professional training & 967 & 0.17 & 0.37 & 197 & 0.18 & 0.38 & \\
\hline University student & 967 & 0.04 & 0.19 & 197 & 0.03 & 0.16 & \\
\hline University degree & 967 & 0.38 & 0.48 & 197 & 0.35 & 0.48 & \\
\hline Research degree (e.g., PhD) & 967 & 0.01 & 0.12 & 197 & 0.02 & 0.12 & \\
\hline Income SEK 5,000 & 967 & 0.06 & 0.23 & 197 & 0.08 & 0.27 & \\
\hline Income SEK 15,000 & 967 & 0.21 & 0.41 & 197 & 0.20 & 0.40 & \\
\hline Income SEK 25,000 & 967 & 0.20 & 0.40 & 197 & 0.21 & 0.41 & \\
\hline Income SEK 35,000 & 967 & 0.16 & 0.37 & 197 & 0.15 & 0.36 & \\
\hline Income SEK 45,000 & 967 & 0.11 & 0.31 & 197 & 0.12 & 0.33 & \\
\hline Income SEK 55,000 & 967 & 0.10 & 0.30 & 197 & 0.08 & 0.27 & \\
\hline Income SEK 65,000 & 967 & 0.07 & 0.25 & 197 & 0.06 & 0.23 & \\
\hline Income SEK 75,000 & 967 & 0.04 & 0.20 & 197 & 0.06 & 0.23 & \\
\hline Income SEK 85,000 & 967 & 0.03 & 0.18 & 197 & 0.02 & 0.14 & \\
\hline Income SEK 95,000 & 967 & 0.02 & 0.16 & 197 & 0.03 & 0.17 & \\
\hline Working & 967 & 0.57 & 0.49 & 197 & 0.44 & 0.50 & \\
\hline Unemployed & 967 & 0.07 & 0.25 & 197 & 0.07 & 0.25 & \\
\hline Student & 967 & 0.11 & 0.31 & 197 & 0.04 & 0.19 & \\
\hline Pensioner & 967 & 0.19 & 0.39 & 197 & 0.13 & 0.34 & \\
\hline Other occupation & 967 & 0.06 & 0.23 & 197 & 0.05 & 0.22 & \\
\hline No children & 967 & 0.68 & 0.47 & 197 & 0.67 & 0.47 & \\
\hline One child & 967 & 0.16 & 0.36 & 197 & 0.15 & 0.36 & \\
\hline Two children & 967 & 0.13 & 0.33 & 197 & 0.12 & 0.33 & \\
\hline Three children & 967 & 0.04 & 0.19 & 197 & 0.04 & 0.20 & \\
\hline Four children & 967 & 0.00 & 0.05 & 197 & 0.02 & 0.12 & \\
\hline Five children or more & 967 & 0.00 & 0.05 & 197 & 0.00 & 0.00 & \\
\hline
\end{tabular}

Note: The table shows summary statistics for the two samples we use, the sample with the matched responses from the health behavior and social preferences survey in 2020, matched surveys 2020, and the sample with the matched responses from the health behavior survey 2020 and the survey from 2018, Survey 2018. The comparison data for the whole Swedish population is based on 2020 data. 


\section{Instructions}

\section{D.1 Questions on health behaviors}

\section{D.1.1 Behaviors in response to COVID-19}

To what extent do the following statements describe your current behavior in response to the outbreak of the coronavirus (COVID-19)?

- I try to avoid social contacts in person (for example, I attend fewer social gatherings)

- I inform myself about how the spread of the corona virus can be prevented

- I keep at least two meters distance from other people

- I refrain from private domestic trips outside my home municipality (e.g., to holiday homes and acquaintances)

- I cough and sneeze into my elbow or a tissue instead of the hand

- I touch my face less often than usual

- I wash my hands more often than usual when not at home

Possible answers: 7-point scale from "Does not apply at all" to "Applies very much"

If you exhibited mild symptoms of sickness (e.g., coughing) tomorrow, how much do the following statements apply to your behavior in the next two weeks?

- I self-quarantine

- I immediately inform people who had contact with me

- I wear a mask, or something else to cover my mouth (e.g., a scarf), if I have to leave home

Possible answers: 7-point scale from "Does not apply at all" to "Applies very much" 


\section{D.1.2 Self-isolation}

In the last 7 days, how often did you leave your home to:

- Buy things other than food and medicine (e.g. clothes)

- Do physical activities with other people (e.g. gym, football, tennis, golf, group workouts)?

- Hang out with friends and relatives who do not live in the same household?

Possible answers: "never", "1 times/week", "2 times/week", "3-4 times/week" "5-6 times/week" "7-8 times/week" "more than 8 times/week" Think now about a normal week in April last year. During this week, how often did you..." (options as question above)

\section{D.1.3 Buy mask}

Now we will ask you if you prefer an item or money. A computer will then randomly select 10 participants and they will get what they choose. This means that if you become one of the 10 selected then you will get money if you chose it (in the form of a gift card* distributed by the Enkätfabriken) and a coupon to buy the item if you chose it (the purchase is made anonymously through an online retailer). It is therefore important that you read the information below carefully and answer it truthfully.

*A SuperPresent card gives you a free choice among all gift cards on gogift.com - you can choose from more than 150 store chains.

You should choose between either $\$ 20$ or a cloth facemask (the mask is worth about $\$ 25$ ). Now follows some important information about facemasks:

- Using a cloth facemask reduces the risk of infecting other people. Since people without symptoms can still spread the infection, expert authorities in several countries recommend covering their face in public places to protect others.

- Cloth facemasks are often not effective at protecting oneself against getting sick. This is a reason why the cloth facemask that you would get would not be used by healthcare professionals, so you do not have to worry that your choice would reduce the availability of protection for healthcare professionals. 
An image of the cloth facemask that you would get:

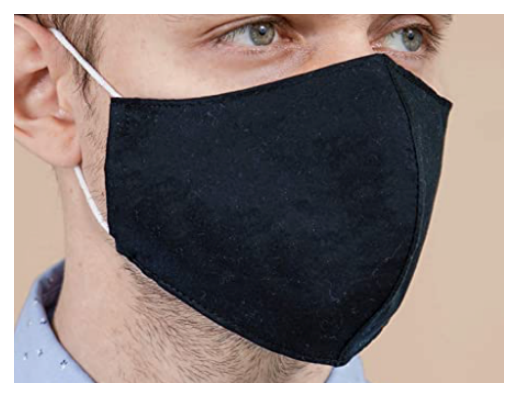

What do you choose? (Cloth facemask, $200 \mathrm{kr}$ )

\section{D.1.4 Donation to solidarity response}

Now we will ask you how much of $\$ 20$ you want to donate to fight the spread of COVID-19. You will keep whatever is left of the $\$ 20$ after you have made your donation. A computer will then randomly select 10 participants and they will get what they choose. This means that if you become one of the 10 selected then we will make the donation for the money you choose below and you will receive the rest (in the form of a gift card distributed by the Enkätfabriken). It is therefore important that you read the information below carefully and answer it truthfully.

The World Health Organization (WHO) and UNICEF have started a solidarity fund to fight the pandemic. The fund will provide resources to educate and equip the community and healthcare professionals to prevent, detect and treat COVID-19. It will help countries expand their healthcare capacity and mitigate the negative social effects, especially for women, children and vulnerable groups.

How much do you want to donate? $(0 \mathrm{kr}, 10 \mathrm{kr}, 20 \mathrm{kr}, \ldots, 100 \mathrm{kr})$

\section{D.1.5 Links}

The outbreak of the coronavirus (COVID-19) is a threat to many people's health. In what follows, we want to take the opportunity to inform you about how you can help mitigate the effects of the virus outbreak.

In the following links you will find more information on how you can contribute.

1. The Swedish Red Cross is very active in helping the weakest and buying equipment for healthcare professionals in Sweden and the rest of the world. Follow this link (opens in 
a new window) to learn more about what they are doing and how you can contribute to this work.

2. It is very important not only to know how to protect yourself but also how to protect others from becoming infected. Follow this link (opens in a new window) to learn about the latest updates from the Public Health Authority on how to help others.

3. Many are worried that during these times, there will be a large lack of blood in Sweden and that many will die because they do not receive blood on time. Follow this link (opens in a new window) to learn more about how to donate by donating blood.

\section{D.2 Social preferences and risk preferences}

In the following decision situations, you will be matched with another person participating in the study. Both you and the other person are endowed $100 \mathrm{kr}$ each. You will then be able to choose a higher payment, but in that case you will risk affecting the other person's payment. There is a risk that the other loses their $100 \mathrm{kr}$. Remember that your answers are confidential.

In total, you will be faced with five decision situations, all of which are similar to the example below. In each situation, you are asked to choose from six different options. For example, in one of these situations, you will choose from the following six options:

\begin{tabular}{ccccccc}
\hline \hline Option & 1 & 2 & 3 & 4 & 5 & 6 \\
\hline Your payment & $100 \mathrm{kr}$ & $120 \mathrm{kr}$ & $140 \mathrm{kr}$ & $160 \mathrm{kr}$ & $180 \mathrm{kr}$ & $200 \mathrm{kr}$ \\
\hline $\begin{array}{c}\text { Probability that the other } \\
\text { person loses 100 kr }\end{array}$ & $0 \%$ & $20 \%$ & $40 \%$ & $60 \%$ & $80 \%$ & $100 \%$ \\
\hline \hline
\end{tabular}

Examples about how your and the other person's payments are affected by your choice:

- If you choose option 1, your payment is $100 \mathrm{kr}$, and the other person will not lose her endowment and therefore earn $100 \mathrm{kr}$.

- If you choose option 4, your payment is $160 \mathrm{kr}$, but there is a probability of 60 percent that the other person loses his/her endowment of $100 \mathrm{kr}$.

We now ask you to answer the following questions where you should assume that the example above is the question selected for payment. 
1. If you choose option 3, how much will you earn (in kr)? (100 kr, $120 \mathrm{kr}, \ldots, 200 \mathrm{kr}$ )

2. If you choose option 3, how high is the risk that the other person will lose his/her endowment of $100 \mathrm{kr} ?(0$

3. Select the correct answer: If you are selected for payment, (I will be paid for all my decisions, I will be paid based on one randomly selected decision)

\section{Choice 1 out of 5}

Summary instructions

- You are matched with another person who participated in a similar survey

- The other person is endowed with $100 \mathrm{kr}$

- You have make a decision that may affect your payment

- Your choice affects the other person: there is a risk that the other person loses his/her $100 \mathrm{kr}$

Please, look carefully at the 6 options that you have below and make your choice. Note that the options may be different from the ones you saw in the previous screen. Which option do you choose?

\begin{tabular}{ccccccc}
\hline \hline Option & 1 & 2 & 3 & 4 & 5 & 6 \\
\hline Your payment & $100 \mathrm{kr}$ & $105 \mathrm{kr}$ & $110 \mathrm{kr}$ & $115 \mathrm{kr}$ & $120 \mathrm{kr}$ & $125 \mathrm{kr}$ \\
\hline $\begin{array}{c}\text { Probability that the other } \\
\text { person loses 100 kr }\end{array}$ & $0 \%$ & $20 \%$ & $40 \%$ & $60 \%$ & $80 \%$ & $100 \%$ \\
\hline \hline
\end{tabular}

\section{Choice 2 out of 5}

Please, look carefully at the following 6 new options that you have below and make your choice.

\begin{tabular}{ccccccc}
\hline \hline Option & 1 & 2 & 3 & 4 & 5 & 6 \\
\hline Your payment & $100 \mathrm{kr}$ & $110 \mathrm{kr}$ & $120 \mathrm{kr}$ & $130 \mathrm{kr}$ & $140 \mathrm{kr}$ & $150 \mathrm{kr}$ \\
\hline $\begin{array}{c}\text { Probability that the other } \\
\text { person loses 100 kr }\end{array}$ & $0 \%$ & $20 \%$ & $40 \%$ & $60 \%$ & $80 \%$ & $100 \%$ \\
\hline \hline
\end{tabular}

\section{Choice 3 out of 5}


Please, look carefully at the following 6 new options that you have below and make your choice.

\begin{tabular}{ccccccc}
\hline \hline Option & 1 & 2 & 3 & 4 & 5 & 6 \\
\hline Your payment & $100 \mathrm{kr}$ & $120 \mathrm{kr}$ & $140 \mathrm{kr}$ & $160 \mathrm{kr}$ & $180 \mathrm{kr}$ & $200 \mathrm{kr}$ \\
\hline $\begin{array}{c}\text { Probability that the other } \\
\text { person loses 100 kr }\end{array}$ & $0 \%$ & $20 \%$ & $40 \%$ & $60 \%$ & $80 \%$ & $100 \%$ \\
\hline \hline
\end{tabular}

\section{Choice 4 out of 5}

Please, look carefully at the following 6 new options that you have below and make your choice.

\begin{tabular}{ccccccc}
\hline \hline Option & 1 & 2 & 3 & 4 & 5 & 6 \\
\hline Your payment & $100 \mathrm{kr}$ & $150 \mathrm{kr}$ & $200 \mathrm{kr}$ & $250 \mathrm{kr}$ & $300 \mathrm{kr}$ & $350 \mathrm{kr}$ \\
\hline $\begin{array}{c}\text { Probability that the other } \\
\text { person loses 100 kr }\end{array}$ & $0 \%$ & $20 \%$ & $40 \%$ & $60 \%$ & $80 \%$ & $100 \%$ \\
\hline \hline
\end{tabular}

\section{Choice 5 out of 5}

Please, look carefully at the following 6 new options that you have below and make your choice.

\begin{tabular}{ccccccc}
\hline \hline Option & 1 & 2 & 3 & 4 & 5 & 6 \\
\hline Your payment & $100 \mathrm{kr}$ & $200 \mathrm{kr}$ & $300 \mathrm{kr}$ & $400 \mathrm{kr}$ & $500 \mathrm{kr}$ & $600 \mathrm{kr}$ \\
\hline $\begin{array}{c}\text { Probability that the other } \\
\text { person loses 100 kr }\end{array}$ & $0 \%$ & $20 \%$ & $40 \%$ & $60 \%$ & $80 \%$ & $100 \%$ \\
\hline \hline
\end{tabular}

You will now again be able to make choices that can affect your payment.

In Choice 6, you start with $100 \mathrm{kr}$. You are asked to choose how much of this money you want to invest in a risky asset. You can consider investing $0 \mathrm{kr}, 20 \mathrm{kr}, 40 \mathrm{kr}, 60 \mathrm{kr}, 80 \mathrm{kr}$, or $100 \mathrm{kr}$. You keep the money you do not invest.

The risky investment: After choosing how much you want to invest, a computer program randomly decides whether the investment is successful or not.

There is a $50 \%$ chance that the investment will fail. If the investment fails, you lose the money you invested. There is a $50 \%$ chance that the investment will succeed. If the investment is successful, you will receive 2.5 times the amount you invested.

The following table describes the payment for the different investment levels if the investment fails or succeeds: 


\begin{tabular}{ccccccc}
\hline \hline Option & 1 & 2 & 3 & 4 & 5 & 6 \\
\hline Payment if investment fails (50\%) & $100 \mathrm{kr}$ & $80 \mathrm{kr}$ & $60 \mathrm{kr}$ & $40 \mathrm{kr}$ & $20 \mathrm{kr}$ & $0 \mathrm{kr}$ \\
\hline Payment if investment succeeds (50\%) & $100 \mathrm{kr}$ & $130 \mathrm{kr}$ & $160 \mathrm{kr}$ & $190 \mathrm{kr}$ & $220 \mathrm{kr}$ & $250 \mathrm{kr}$ \\
\hline \hline
\end{tabular}

Examples:

- If you invest $0 \mathrm{kr}$ your payment will be $100 \mathrm{kr}$ for sure.

- If you invest $60 \mathrm{kr}$ and the investment fails (which happens with $50 \%$ chance) your payment will be $40 \mathrm{kr}$. If the investment succeeds (which happens with $50 \%$ chance) your payment will be instead $190 \mathrm{kr}$.

We ask you to answer the following questions:

1. If you invest $40 \mathrm{kr}$ and the investment fails, how much do you earn? $(0 \mathrm{kr}, 20 \mathrm{kr}, \ldots$ $, 100 \mathrm{kr})$

2. If you invest $40 \mathrm{kr}$ and the investment succeeds, how much do you earn? (100 kr, 130 kr, $160 \mathrm{kr}, 190 \mathrm{kr}, 220 \mathrm{kr}, 250 \mathrm{kr}$ )

\section{Choice 6}

How much do you invest?

- $0 \mathrm{kr}$ : Gives $100 \mathrm{kr}$ if the investment fails, and $100 \mathrm{kr}$ if it succeeds

- $20 \mathrm{kr}$ : Gives $80 \mathrm{kr}$ if the investment fails, and $130 \mathrm{kr}$ if it succeeds

- $40 \mathrm{kr}$ : Gives $60 \mathrm{kr}$ if the investment fails, and $160 \mathrm{kr}$ if it succeeds

- $60 \mathrm{kr}$ : Gives $40 \mathrm{kr}$ if the investment fails, and $190 \mathrm{kr}$ if it succeeds

- $80 \mathrm{kr}$ : Gives $20 \mathrm{kr}$ if the investment fails, and $220 \mathrm{kr}$ if it succeeds

- $100 \mathrm{kr}$ : Gives $0 \mathrm{kr}$ if the investment fails, and $250 \mathrm{kr}$ if it succeeds

Now we ask you to guess how much the other participants choose to invest.

What do you think that most other participants in this survey choose?

- $0 \mathrm{kr}$ : Gives $100 \mathrm{kr}$ if the investment fails, and $100 \mathrm{kr}$ if it succeeds

- $20 \mathrm{kr}$ : Gives $80 \mathrm{kr}$ if the investment fails, and $130 \mathrm{kr}$ if it succeeds 
- $40 \mathrm{kr}$ : Gives $60 \mathrm{kr}$ if the investment fails, and $160 \mathrm{kr}$ if it succeeds

- $60 \mathrm{kr}$ : Gives $40 \mathrm{kr}$ if the investment fails, and $190 \mathrm{kr}$ if it succeeds

- $80 \mathrm{kr}$ : Gives $20 \mathrm{kr}$ if the investment fails, and $220 \mathrm{kr}$ if it succeeds

- $100 \mathrm{kr}$ : Gives $0 \mathrm{kr}$ if the investment fails, and $250 \mathrm{kr}$ if it succeeds

\section{D.3 Personality measures, time preferences, health and worries}

Here is a series of 10 statements that might apply to you. Please read each statement and decide how much you agree or disagree with that statement. Then pick the element of the following scale that best represents your position:

Please answer every statement, even if you are not completely sure of your response.

- Extraverted, enthusiastic.

- Critical, quarrelsome.

- Dependable, self-disciplined.

- Anxious, easily upset.

- Open to new experiences, complex.

- Reserved, quiet.

- Sympathetic, warm.

- Disorganized, careless.

- Calm, emotionally stable.

- Conventional, uncreative.

Possible answers: 7-point scale from "Strongly disagree" to "Strongly agree"

How well does each of the following statements describe you as a person? Please indicate your answer on a scale from 0 to 10. A 0 means "does not describe me at all," and a 10 means "describes me perfectly." You can use any number between 0 and 10 to indicate where you fall on the scale, using $0,1,2,3,4,5,6,7,8,9$, or 10 . 
- I assume that people have only the best intentions.

We now ask you for your willingness to act in a certain way. Please again indicate your answer on a scale from 0 to 10. A 0 means "completely unwilling to do so," and a 10 means "very willing to do so." You can also use any number between 0 and 10 to indicate where you fall on the scale, using $0,1,2,3,4,5,6,7,8,9$, or 10 .

- How willing are you to give to good causes without expecting anything in return?

- How willing are you to give up something that is beneficial for you today in order to benefit more from that in the future?

Imagine the following situation: You receive unexpectedly 18,000 SEK today. How much of that sum would you donate to a charitable cause? (Values between 0 and 18000 are allowed)

How long do you think you will live? Please introduce the age that you expect to reach. (values between 18 and 100 are allowed)

To what extent do the following statements describe your concerns about the ongoing outbreak of the coronavirus (COVID-19)

- I'm worried about getting infected

- I am worried that healthcare will not be able to offer good care to everyone

- I am worried that my finances will be hit hard

- I am worried that the Swedish economy will be hit hard

- Sweden has responded strongly enough

- I believe that physical distancing is important to overcome the outbreak of viruses

Possible answers: 7-point scale from "does not apply at all" to "applies very much" 